\title{
WHAT CHILDREN THINK, FEEL, AND KNOW ABOUT PHYSICAL FITNESS TESTING
}

by

\author{
Christine J. Hopple \\ Thesis submitted to the Faculty of the \\ Virginia Polytechnic Institute and State University \\ in partial fulfillment of the requirements for the degree of \\ MASTER OF SCIENCE
}

in

Education
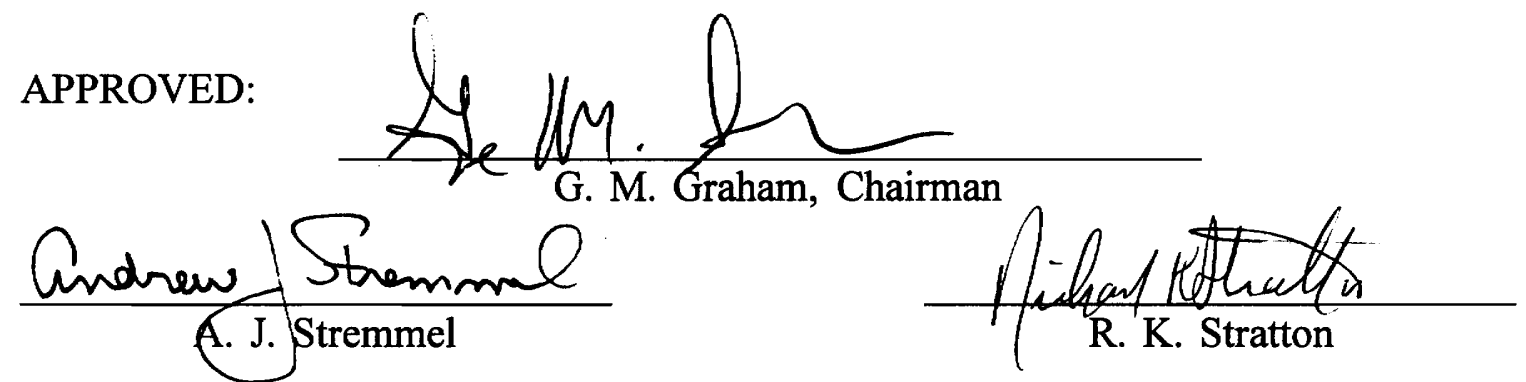

May, 1994

Blacksburg, Virginia 


$$
\begin{aligned}
& \angle D \\
& 5655 \\
& V 855 \\
& 1994 \\
& H 677 \\
& C .2
\end{aligned}
$$




\title{
WHAT CHILDREN THINK, FEEL, AND KNOW ABOUT PHYSICAL FITNESS TESTING
}

\author{
by \\ Christine J. Hopple \\ Committee Chairman: George M. Graham \\ Health and Physical Education
}

\section{(ABSTRACT)}

For thousands of students this year alone, taking the physical fitness tests will be as much a part of the annual school routine as is the first day of school, lunch, and standardized tests in the classroom. Given this, it becomes relevant to gain some insights into what students think, feel, and know about these tests. For example, do students know why they take the test items? How to improve their performance on the test items? What do they think about taking the tests? Do students who perform well on the tests think differently than those who don't?

To answer questions like the above, 54 students in the fourth and fifth grades from two different schools were interviewed two-at-a-time using a semi-structured interview format. Interviews with physical education and other school staff were also conducted to provide for multiple sources of data (triangulation).

Audiotaped interviews were transcribed, numbered line-by-line, and analyzed according to qualitative methods. Assertions were developed which were supported by the data. Results indicate that most students have an incomplete, concrete understanding of the purposes and concepts pertaining to the physical fitness tests. Teacher's urging or encouraging behaviors during test administration have a large 
effect on students feelings about taking the tests, and many times students, especially those who tend to score poorly on the tests, receive negative feedback from their peers in the form of ridicule and embarrassment. 


\section{ACKNOWLEDGEMENTS}

It is said that all good things take time. If that's so, then, this thesis could be considered a masterpiece! Seriously, though, finishing this thesis and my degree wouldn't be a reality but for the support and encouragement I've received from many. First and foremost, thanks must go to my advisor, Dr. George Graham. Thank you, George, for "stretching" my thinking with your simple question "So what did they really learn?", and for your ever-present encouragement and belief in me as both a teacher and a person. Your dedication to elementary physical education and children sets an example I can only hope to one day reach.

To Drs. Andy Stremmel, Richard Stratton, and Gail Webster, as well as the teachers and children who participated in this study: thank you all for your time and help. Special thanks to my fellow grad students, especially Mark and Rosie, for your humor, support, and (perhaps most of all) for listening! Thanks, too, to my friends in Room 226, WMH. I have certainly been blessed to have you in my "Virginia" life!

I must also thank my many "Florida" friends and colleagues, especially Manny, Tom, Jodi, Vicki, John S., Dr. Jones, Lynda R., and the students of College Park Primary School. Each of you has played a part in getting me to who, and where, I am today. This thesis is as much a reflection of you as it is of me. And finally, thanks to my friends in my "Illinois" life, who have endured listening to the many trials and tribulations involved with the preparation of this thesis. Finally, I can say "It's done"! 


\section{TABLE OF CONTENTS}

Section

Page Number

Title Page

i

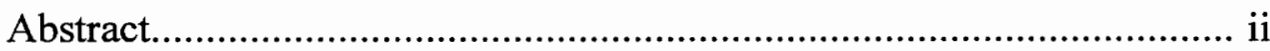

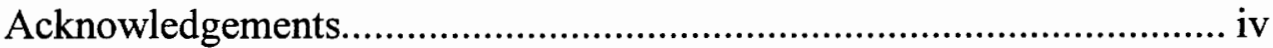

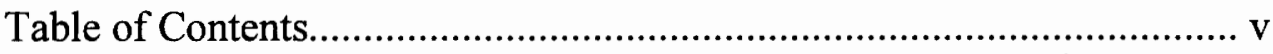

List of Tables........................................................................................

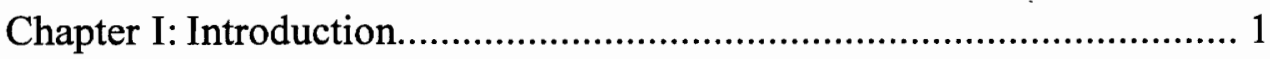

Chapter II: Review of Literature......................................................... 13

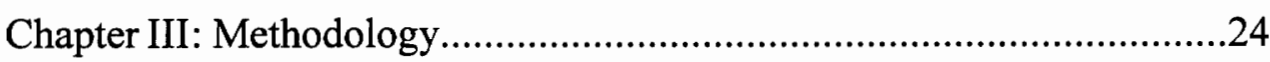

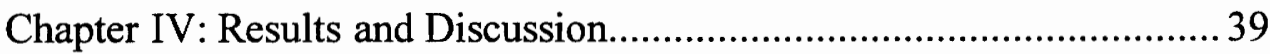

Chapter V: Conclusions, Implications, and Recommendations.............. 117

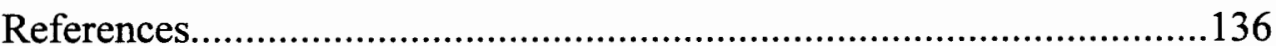

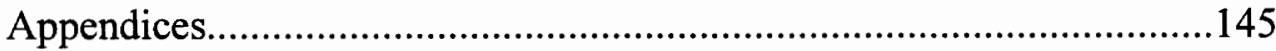

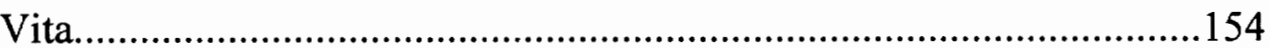




\section{LIST OF TABLES}

Table Number and Title

Page Number

Table 1. All Students - School A vs. School B .48

Table 2. All Student by Test Score 50

Table 3. All Students by Scores and by School .52

Table 4. Interviewed Students with Lower vs. Higher Test Scores 53

Table 5. All Boys vs. Girls -- Both Schools. 54

Table 6. All Boys vs. Girls -- by School .55 


\section{CHAPTER I}

Introduction

The importance of being physically fit and active as a necessary ingredient for a healthy lifestyle has been increasingly stressed over the past decade. During this time we have learned, for example, that regular participation in work-time and leisure-time physical activity by adults is associated with increased longevity (Blair, Clark, Cureton, \& Powell, 1989) and decreased risk of coronary heart disease (Paffenberger \& Hyde, 1984). Adults, however, are not the only population for which this increased emphasis has become important. Children also have a need for frequent physical activity. Specific components of health-related physical fitness of elementary school students have declined over the past two decades; $25 \%$ of $6-11$ year old children are considered overweight (Bar-Or, 1987); and unfit and overweight children are exhibiting early signs of elevated blood pressure, high cholesterol levels, and coronary heart disease. These facts, in combination with the logical relationship between physical activity during childhood and future activity patterns as an adult, have led to an increase in research focusing on children's health and physical fitness.

Organizations such as the American Alliance for Health, Physical Education, Recreation, and Dance (AAHPERD) and the U.S. Department of Health and Human Services (USDHHS) have been instrumental in the recent formulation of nationwide objectives for childhood health, physical fitness, and physical activity. For example, 
in their document Healthy People 2000, the USDHHS states that by the year 2000, "...at least 30 percent...of people aged 6 and older should engage regularly, preferably daily, in light to moderate physical activity for at least 30 minutes per day" (1991, p. 91).

Another example is shown by the Outcomes Project of the National Association of Sport and Physical Education (NASPE), which has defined what a "physically educated person has, does, is, knows, and values" (Franck, Graham, Lawson, Loughery, Ritson, Sanborn, \& Seefeldt, 1990, p. 7). According to this committee of national experts, a person who is physically educated, in part, "selects and regularly participates in lifetime physical activities; participates in health enhancing physical activity at least three times a week; assesses, achieves, and maintains physical fitness; and cherishes the feelings that result from regular participation in physical activity" (Franck, et. al., p. 7).

Many consider public school physical education programs as the most likely vehicle for accomplishing objectives such as those outlined above by NASPE and the USDHHS. For example, many programs now stress the learning of physical fitness concepts as a regular part of the elementary physical education curriculum, and involving students in both developmentally and instructionally appropriate health and fitness-related activities both in and out of school has become a major focus of instruction for many teachers. In addition, the assessment of children's physical fitness levels continues to be the responsibility of the elementary physical education 
specialist.

Given this tremendous emphasis by physical education teachers on involving students in fitness-related activities, knowledges, and testing, it becomes logical to ask if physical education programs are indeed helping students to achieve nationallyrecognized goals for physical health and well-being (Simons-Morton, O'Hara, Simons-Morton, \& Parcel, 1987). More specifically, given that physical fitness tests are administered to thousands of elementary school children annually and they continue to be the most widely used form of assessment in physical education programs across the country, it becomes important to focus on their role in helping students to become "physically educated".

This emphasis on determining how the fitness tests are used with and impact on students is supported by many leading experts in physical education. During the past five years, the use of the tests have especially come under major criticism; many have called for a rethinking of both why and how teachers give the physical fitness tests. Whitehead crystallizes this position by agreeing with Fox and Biddle's thoughts that "fitness tests in the past...have not been used to help achieve the objectives of well-designed educational plans, or have been used for the wrong reasons -- such as for determining class grades. In contrast, recently designed packages (tests) do not use fitness tests as an end in themselves, but rather as tools that facilitate the educational process" $(1989$, p. 40$)$.

In support of a change in why physical educators administer the tests and use 
the results, Corbin \& Fox (1985) speak for many (Freedson \& Rowland, 1992; McSwegin \& Mielke, 1989; McSwegin, Pemberton, \& Petray, 1989; Ratliffe \& Ratliffe, 1994) when they suggest that the tests should help students attain higher order physical fitness goals. These goals include students' use of test scores for developing and implementing their own personal fitness plans; that students understand activities designed to help them increase their levels of health-related fitness; and that students come to value physical activity.

Too, a change in how the physical fitness tests are being used and administered to children has come under close scrutiny by physical educators. Part of this increased emphasis is a result of the recent focus on critically looking at elementary physical education practices in terms of their developmental appropriateness for children. For example, the Council on Physical Education for Children (COPEC) of NASPE gives the following as appropriate uses of the tests: Ongoing fitness assessment is used as a part of the ongoing process of helping children understand, enjoy, improve and/or maintain their physical health and well-being. Test results are shared privately with children and their parents as a tool for developing their physical fitness knowledge, understanding and competence. As part of an ongoing program of physical education, children are physically prepared so they can safely complete each component of a physical test battery. (NASPE, 1992, p. 8)

Conversely, they describe the following as inappropriate uses of the tests: 
Physical fitness tests are given once or twice a year solely for the purpose of qualifying children for awards or because they are required by a school district or state department. Children are required to complete a fitness test battery without understanding why they are performing the tests or the implications of their individual results as they apply to their future health and well-being. [And] Children are required to take physical fitness tests without adequate conditioning (e.g. students are made to run a mile after "practicing" it only one day the week before). (NASPE, 1992, p.'9)

That misuse of the tests can be detrimental to some students is supported by Kraft when he states, "the administration of standardized fitness and skills tests, where scores are compared to normative data, can result in a negative experience for the majority of students. Students with motor deficiencies may view tests in physical education classes as an unpleasant experience to be avoided" (1989, p. 18).

Thus, given the emphasis on the use of the physical fitness tests as more than just a testing procedure and an educationally appropriate experience, it becomes important to look further into their actual use with and impact on children. For example, do physical fitness tests help students gain an understanding about the components of fitness? Are these tests helping to promote positive feelings towards physical activity for all students? Do students know what activities help them achieve better levels of health-related fitness both now and in the future? Do they understand how physical fitness test results can serve as an aid to developing and 
achieving their own personal fitness? And, do students view the taking of the tests in a positive light? Pate (1991) acknowledges similar concerns to these when he states, "it would be desirable to know how children respond to participation in these tests... Are tests viewed as fun? Do tests have differential effects on different types of children? Though irrelevant from a strict measurement perspective, these issues may determine appropriateness of fitness testing in the school setting" (p. 233). If we are to help students achieve their fullest physical potential, then, and become physically educated, it seems that answers to questions such as these can become extremely important.

\section{Statement of the Purpose}

The purpose of this study was to determine what fourth and fifth grade students think, feel, and know about one physical fitness test battery and the test items in that battery. Four major research questions were used to guide the interviews with the students:

1. Did children understand the reason(s) why they took the physical fitness tests? Did they understand what the test items measured? Did they understand the implication of good, or poor, performance on the test items?

2. Did children understand how to improve their performances on each test item?

3. What did the children think, in general, about the physical fitness tests? Were they important to them? What did they like about them? Not like? 
4. What did children think about their scores on the fitness tests? Did they think their parents felt their scores were important?

5. Were there any differences in how students who tend to score well, versus poorly, responded to the above questions?

\section{Assumptions}

It was assumed, for the purposes of this study, that all students, teachers, and administrators would reflect their honest opinions during the interviews.

\section{Limitations of the Study}

1. Physical education programs at which data were collected were existing and on-going prior to the date of collection.

2. Both programs used only one physical fitness test, the President's Challenge, for their fitness testing purposes.

3. The researcher was not present at the school sites at the time of the physical fitness test administration or when concepts relating to testing and fitness were explained.

\section{Delimitations of the Study}

1. The students interviewed in this research represent fourth and fifth graders at only two different schools in one school district.

2. Only students who had already taken the fitness test at their present school (either A or B) during the previous Fall and whose scores were recorded were a part of this study. 


\section{Operational Definitions}

1. "Students who tend to score poorly on the tests": those students who scored below the 50th percentile on the mile run and two of the four remaining fitness test items (i.e. shuttle run, sit-and-reach, pull-ups, and curl-ups).

2. "Students who tend to score well on the tests": those students who scored above the 50th percentile on the mile-run and at least two of the remaining fitness test items.

3. "Average" Scores: Those scores which do not belong into either of the above two categories.

4. President's Challenge Physical Fitness Test: a test battery composed of five test items: one mile run/walk as a measure of cardiorespiratory endurance; bent-knee curl-ups (abdominal muscle strength and endurance); pull-ups (arm and shoulder girdle strength); sit-and-reach or v-sit (flexibility of lower-back and hamstrings); and shuttle run (agility) (Safrit, 1990).

\section{Research Hypotheses}

It was hypothesized that the following conclusions would be reached for the children who participated in this study:

1. Students who tended to score poorly on the tests would exhibit a greater dislike for the physical fitness test battery and test items in that battery, and value them less than students who tended to score well on the tests;

2. Those students who tended to score well would have more positive 
thoughts, feelings, and values regarding the physical fitness test and test items than those students who scored poorly on the tests;

3. The knowledge students displayed regarding the physical fitness test battery and test items in that battery would be influenced in part by experiences in their physical education class.

\section{Author Bias}

A recognized bias of the researcher prior to data collection was that students at School A would show a greater understanding of why they took the physical fitness test battery and the purpose of the items in that battery than students at School B, due to receiving formal instruction on concepts relating to fitness. As such, every attempt was made to keep this bias from affecting the process of interpreting results of the research.

\section{$\underline{\text { Significance }}$}

Many have suggested that the physical fitness levels of children have declined over the past decade; some of this data comes from results of nationwide physical fitness test batteries which children take in physical education classes at school. These test batteries are the most widely used test in elementary physical education; thousands of children take them annually. And while some research in recent years has focused on the tests and test scores in terms of whether they are valid and reliable measures of children's fitness levels (Safrit \& Looney, 1992; Woods, Pate, \& Burgess, 1992), little to no interpretive or qualitative research has 
been conducted to determine how, or if, these tests and test items impact upon the attitudes and knowledge of the children who are subjected to taking them each year.

Research of this kind, if done, has the potential to make an impact upon the use of the tests by teachers and children in the real world of the gymnasium. Outside physical education, for example, qualitative studies have shown to be of importance to how teachers instruct. They have shown that when teachers understand how children learn, think, and feel about a certain subject or topic, this information can influence and change how they instruct in that area (Bondy', 1990; Carpenter, Fennema, Peterson, Chiang, \& Loef, 1989). Alton-Lee and Nuthall (1990) report that what teachers think is being taught, and what children are actually learning, can be very different. Closer to the gymnasium, Lawson, Lawson, and Stevens (1982) found through interviewing children about their general physical education experiences that they liked exercising, didn't know about the effects of doing this (even if they thought they did), and they wanted to know more about what happened with their bodies when exercising. These authors go on to state that they feel the use of qualitative assessments such as interviews by teachers could be important in finding out just what children are thinking and know about a topic -- thoughts that might otherwise go untouched. It is possible, then, that information gathered from children as a part of this study may be able to impact upon how physical education teachers view the physical fitness tests and test items and how they relate to children. Again, no research to date has focused upon these aspects of the physical fitness tests. 
In conclusion, many leading researchers and educators have called for a change in how the physical fitness tests and test results, especially, are used in an educational setting (Corbin, 1987; McSwegin, 1989). By delving into the thoughts and feelings which children may have regarding these, elementary physical educators can gain a broader view of how the test results and procedures associated with them impact upon children's feelings, knowledge, and possibly even their relation to activity patterns in the future. Whitehead and Corbin, in their discussion on the problems of conducting quantitative research in valid field situations, tell us that "it may be advantageous to employ qualitative approaches rather than relying solely on the scientific method" (to further understand where the discrepancies between results and hypotheses lie) (1991, p. 15). Yonemura, too, says that the use of a one-on-one interview with children as a qualitative measure of what they know and feel give us that vehicle by which to gain a "deeper view of child thought" (1974, p. 65). Given, then, the lack of qualitative data regarding children and the physical fitness tests and the promise of what it can tell us, this study holds significance for other researchers and educators in physical education and is of worthwhile effort on the part of the researcher.

\section{Summary}

This study attempted to answer some of the above questions, and others that are related but have not been addressed in the literature, by discerning what children think, feel, and know about the physical fitness 
tests. While literature regarding students' attitudes towards physical activity can be found, the measurements used tend to be quantitative in nature and therefore, slightly limited in the insights they are able to give us. Therefore, the thoughts and feelings of students gained through qualitative measures have the possibility of providing physical educators with helpful insights for making physical fitness test experiences as meaningful as possible to the children in their classes. Hopefully, these meaningful physical fitness experiences early in life will result in meaningful experiences for these children as they progress into adulthood. 


\section{CHAPTER II}

\section{Review of Literature}

Three main areas of literature relating to the topic of children and physical fitness will be discussed in this review as they are relevant to the purpose of this study. These include: 1) the importance and value of physical fitness; 2) the physical fitness tests and criticisms associated with them; and 3) the value of interpretive research and how it relates to research on children.

\section{The Importance and Value of Physical Fitness}

Good health includes being physically fit. It is commonly accepted that at least a minimal level of physical fitness is a necessary component for a healthy lifestyle (Corbin, 1987; Simons-Morton, O’Hara, Parcel, Huang, Baranowski, \& Wilson, 1990). Too, it is widely supported through research that certain health-risk factors can be decreased by regular exercise. These health-risk factors include coronary heart disease, high blood pressure, and obesity (Paffenbarger \& Hyde, 1984).

This link between fitness and proper health helped initiate the fitness craze of the 1980's. During this time, many adults began participating in regular physical activity. Even so, however, a large proportion of the adult population in the United States still leads a sedentary life (Simons-Morton, et. al., 1990; Stephens, Jacobs, \& White, 1985). Because of this, a large number of adults are at risk for many of the afore-mentioned health factors which could be reduced by regular exercise. 
Due to the increased emphasis on adult fitness and health levels, many researchers have begun to examine the physical fitness and health levels of our nation's children. For example, both National Children's Youth and Fitness Studies (conducted in the 1980's) reports that most children, like adults, do not receive the proper amount of physical activity they need in order to stay physically fit (Ross \& Gilbert, 1985; Ross \& Pate, 1987). Although some researchers disagree (Blair, 1992; Corbin \& Pangrazi, 1992), other studies suggest that overall physical fitness levels of young children in the United States have declined over the past twenty years (Loper, Scheer, Ansorge, Bahls, \& Wandzilak, 1989; Pate, Ross, Dotson, \& Gilbert, 1985). Additional studies agree that childrens' levels of specific components of health-related fitness, namely that of cardiovascular fitness and body composition, have indeed worsened over the past decade (Blair, 1992; Kuntzleman \& Reiff, 1992; Updyke, 1992). Bar-Or's (1987) statement that approximately $25 \%$ of six to eleven year old children are considered overweight and Rowland's finding (1992) that obesity now affects $10-20 \%$ of children seem to support the recent research finding .

The lack of adequate physical activity and achievement of minimal physical fitness levels by children is considered of major importance as health-risk factors such as coronary heart disease, high cholesterol levels, and elevated blood pressure have begun to appear in overweight and unfit children (Dishman \& Dunn, 1988; Gillium, Katch, Thorland, \& Weltman, 1977; McSweegin, 1989; Ross \& Pate, 1987; Walberg \& Ward, 1985). Because these risks can carry over into adulthood, there 
has been a call for the need to improve the levels of children's physical fitness in order to counteract these health risks. This call has resulted in an enormous interest by physical educators for activities and programs which will increase children's fitness levels, as well as in the use of the physical fitness tests.

Many researchers and practitioners, however, have gone farther than simply stating a need for increased physical fitness for children; they suggest that merely achieving physical fitness at an early age will not guarantee an acceptable level of fitness in adulthood (Michaud \& Andres, 1990; Simons-Morton, et. al, 1990). McSwegin, Pemberton, and Petray summarize this view with the statement, "...the challenge of fitness is not just in getting children and youth physically fit; the challenge is in getting them fit and educating them to stay fit for life" $(1989$, p. 32).

As reflected in statements such as these, there has lately been an increased emphasis on the teaching of values and concepts regarding exercise and physical fitness to children. It is becoming increasingly accepted that children should be educated as to what the definition and value of appropriate physical activity and a healthy lifestyle is, so that they may grow up to be "physically educated" adults (Franck, et. al., 1990). By learning fitness concepts early in life, it is hoped that important values - along with a healthier body - will carry over with them into their adulthood (Blackwell, 1990; Colquhoun, 1990; Corbin, 1987; McSwegin, et. al., 1989; Michaud \& Andres, 1990; Ratliffe \& Ratliffe, 1994; Symons \& Gascoigne, 1990). It has also been recognized that physical education programs have become 
the best and most natural location for these values, knowledges, and motivation to be transmitted to children, as a result of its greatest exposure to children in a physical activity context (Michaud \& Andres, 1990; Symons \& Gascoigne, 1990). Therefore, there is -- and will continue to be -- a great emphasis upon physical educators to address the issue of children's fitness and fitness education.

\section{Physical Fitness Tests}

In conjunction with the awareness of the need for and importance of improved physical fitness and activity for children, there has been a call by leading researchers and educators alike for certain practices of the past relating to physical fitness and physical fitness testing to be examined in light of their present and future educational values (Corbin, 1994; Corbin \& Pangrazi, 1993). For example, physical fitness tests have been increasingly criticized as being too much of an "end to itself". Unfortunately for many children, physical fitness test results are sometimes used to determine an individual's physical education grade, are ignored completely once the test is completed, or are used to qualify students for awards. When used in these ways, physical fitness tests many times become significant to the students only in light of their "passing" or "winning". Because of these "one-time only" situations in which a child must perform in order to be successful (i.e. win or pass), "the rich (naturally fit/athletic) get richer and poor (unfit/ungifted) get poorer" (Rutherford, 1990, p. 15). As a result, the intrinsic motivation of the students to participate in future fitness activities because of the healthful benefits and/or feelings of enjoyment 
derived from participating can be seriously undermined (Kraft, 1989; Pemberton \& McSwegin, 1989; Rutherford, 1990).

Another, and perhaps greater, criticism of the physical fitness tests is that they are not seen by physical educators as part of the total educational process for children (McSwegin, 1989; McSwegin \& Mielke, 1989; Pangrazi, 1989; Symons \& Gascoigne, 1990; Ratliffe \& Ratliffe, 1994; Whitehead, 1989). Many times, their evaluative, or diagnostic, promise is ignored. If physical education programs are to help children internalize values and understand the knowledge behind physical fitness, then formal assessment must be seen, according to McSweegin and Mielke, as only "one part of the fitness behavior shaping process...by itself, such testing and evaluation does not provide enough information or motivation to assist students in modifying their actions, knowledge, or beliefs" $(1989$, p. 64). Children must have opportunities to become informed about their test scores, understand and interpret them, develop activity goals based on them, and evaluate their progress towards reaching those goals. The AAHPERD Physical Best Educational Program (AAHPERD, 1988) is one example of how physical fitness tests are being reformed as an educational and motivational tool. Physical Best calls not only for the assessment of children's fitness levels (by assessments such as the Prudential Fitnessgram), but also for children to set future fitness goals, understand what can help them improve in the future, and develop their own fitness programs. This is the "philosophy of the future" in regards to physical fitness tests; studies abound in 
which researchers have called for these and similar goals to be an integral part of the fitness testing experience for children (Going \& Williams, 1989; Hutchinson, Freedson, Ward, \& Rippe, 1990; McSwegin, Pemberton, \& Petray, 1989; Symons \& Gascoigne, 1990). As a result of involving children in the processes of understanding concepts, setting goals, and of making commitments and realistic choices, it is hoped that taking physical fitness tests will become more meaningful, challenging, and enriching to children. While this does take time and the results are not always readily evident, the total process holds much promise for motivating children to increase their health and fitness levels -- not only as children, but for a lifetime.

\section{Value of Interpretive Research}

Before adults can begin to make the physical fitness tests, and related activities, most meaningful and motivating to children, WHAT is seen by children as meaningful and motivating must be considered. As adults, we think in terms of our adult world; however, children - and especially young children - live in a different world (Yonemura, 1974). Essentially, this means that what adults and children think is important and meaningful may not always be the same. Parker (1984) summarized this sentiment by stating, "what we know and do not know about children ought to have a real impact on how we go about educating them" (p.18). Finding out how children learn and what they have learned can allow educators to: determine if they are being effective (Alton-Lee \& Nuthall, 1990; Lawson, et. al., 1982), help them 
make more informed decisions regarding future educational experiences for children (Yonemura, 1974), or change the way in which they teach (Carpenter, et. al, 1989; Commins \& Miramontes, 1989).

One approach for learning about what children know and learn has been labeled interpretive or qualitative-based research (Erickson, 1986; Locke, 1989). This research approach is designed to answer questions such as, what is happening in this situation? What are the subjects thinking? Feeling? Why are they feeling this way? What do they know about their context that they can tell us, and therefore give the deeper, richer meanings not always associated with quantitative research?

The interview is one method for gaining insights into answers to these questions. Interviewing children is a viable opportunity for researchers and educators to discover the "perceptions, attitudes, beliefs, memories, feelings, hopes, judgements, and plans (of children)" (Parker, 1984, p.19). While research methods such as observations, questionnaires, surveys, and attitude scales may help to scratch the surface, interviews are considered a "more direct and reliable access" to these subjective qualities (Parker, 1984, p. 19). Some of the reasons this is so are outlined below.

First, the interview enables children the opportunity to elaborate on their responses. This can be very beneficial in determining the meaning behind a child's answer on a questionnaire, for that answer may reflect a viewpoint different from what the researcher was intending to uncover (i.e. "right" answer, "wrong" reason). 
Without the ability to probe, any discrepancies between a written response and what the child was thinking may not be found (Seda \& Pearson, 1991).

Second, children are not required to communicate their knowledge and feelings on paper in an interview setting. This is especially important for younger children who may not yet have the ability to adequately express themselves in written terms (Parker, 1984). Third, the interview allows for more personal, one-onone contact to be established with the child. This enables the interviewer to observe any non-verbal responses to questions which could at times' be more important, or even conflicting, with what the verbal response was (Measor, 1985).

Fourth, misunderstood questions on surveys, scales, or questionnaires are, in most cases, not able to be rephrased for the better understanding of the child. An interview can allow the researcher to elaborate on or rephrase a question in order to clarify the meaning for the child, if necessary.

Fifth, an experienced interviewer can capitalize on the fact that children enjoy talking in extended conversations with adults whom they perceive to be trusting, responsive, and interested (Rogers, 1987; Davies, as cited in Tammivaara \& Enright, 1986). Talking in such situations allows children to enhance their cognitive, social, and emotional development by discovering things about themselves and others. It enables them to practice communicating their ideas, feelings, and emotions verbally (Rogers, 1987). If properly executed, an interview includes both the researcher and the child holding equal control over the course of the interview (neutral valence), or 
lets the child hold more control (negative valence). This facilitates a feeling of trust and responsiveness in the child (Tammivaara \& Enright, 1986), which can greatly improve the success of the interview.

Last, another advantage for the use of interviews with children is that they allow adults to discern the different thoughts and feelings which children hold. Just as all adults do not feel or think alike, neither do children. Studies show that children with different abilities think, feel, and react differently to certain topics (Harter \& Pike, 1984; Ford, 1989; Weiss, McAuley, Ebbeck, \& Wiese, 1990). Interviews can allow researchers and educators to discover these differences, and as a result make events and educational practices as meaningful for children as possible.

From a "technical" point of view, an interview is also able to be used as a method of validating written information, observations, and/or other data. This is commonly referred to as "triangulation", where multiple data sources serve as a "cross-check" for each other (Denzin, 1970; Morine-Dershimer, 1985).

Taken as a whole, the above reasons seem to uphold the use of interviews as a means of gathering data and learning about children in the context of interpretive research. Up until now, there have been only a limited number of studies which have used interviewing children as a primary means of data collection. Most of these have occurred in various educational settings.

Bondy (1990), for example, interviewed children with different reading 
abilities and was able to describe how children with lesser abilities differed in their thoughts and perceptions pertaining to reading, and the cognitive strategies they used in that subject area. Gifted children's feelings on areas such as their classroom activities, competition, and friendships with other children were discussed by Ford (1989). Commins and Miramontes (1985) used a multi-case study approach to describe the linguistic performance of four bilingual children in and out of school. Seda and Pearson (1991) have used interviews as a way of assessing students' reading comprehension and reasoning behind their specific task performance. And Amato and Ochiltree (1987) interviewed over 300 children about their families in order to compare the quality of data gathered from pre-schoolers and teenagers. (They concluded that the quality of the data -- taking into account problems during interviews such as difficulties in understanding questions and insincerity -- was slightly higher for adolescents than primary students. When one looked at the overall number and quality of interviews, however, the quality of all interviews was high.)

Researchers in physical education have, to date, made limited use of interviewing children. Lawson, et. al. (1982) interviewed elementary school children regarding their physical education experiences and why they liked/disliked physical education. The children's responses, in part, helped the physical education teachers discern the differences between what both these parties, and others such as administrators, perceived as the meaning of physical education. Because the research method of interviewing children has been increasingly used - and successfully so - 
in other subject areas, it seems to also hold promise for future research in physical education, especially when relating to the topic of physical fitness tests.

\section{Summary}

This review of literature focused on three main areas of literature relevant to the purpose of interviewing children about their physical fitness testing experiences and knowledge. The first area described was the importance of physical fitness for children. Literature in this area states that children are at-risk for certain health factors due to a lack of physical activity, and emphasis has begun to be placed upon increasing children's motivation, knowledge, and values regarding physical activity and fitness in their physical education classes. Second, physical fitness test practices of the past are now being replaced by the use of the tests as a diagnostic procedure which allows the tests to be part of the total educational experience for children. The last area was that of interpretive research and how it relates to research on children. Interpretive research, and the use of interviews, especially, is seen as a promising method of discovering the thoughts, feelings, and perceptions of children. A lack of research in physical education suggests a need for further research which utilizes this method of data collection. 


\section{CHAPTER III}

\section{Methodology}

This study was designed to determine what fourth and fifth grade students, especially those who tend to score well, and poorly, on the tests thought, felt, and knew about one physical fitness test battery and the test items in that battery. The use of interviews in this study provided insights into the most widely used and accepted test in children's physical education programs in the United States of America.

\section{Setting}

This study was conducted at two different schools located in the same school district in a medium-sized county in a large southeastern state. Both schools offered 30 minutes of physical education daily for first through fifth graders taught by physical education specialists.

\section{$\underline{\text { School A }}$}

School A is a combination K-5, 6-8 school housed on the same school site in a predominately rural area. The elementary school $(\mathrm{K}-5)$ is separate from the middle school and has its own physical education equipment, facilities, and teachers. There are two full-time specialists at the school. Both have considerable experience teaching students in grades K-5; "Amanda" (pseudonyms used for all teachers and students) had 13 years experience and "Andrew" 21 years at the time this study was conducted. The teachers at School A alternated units of instruction with classes of 
students throughout the year, so that each teacher instructed all K-5 graders in one content "unit" as the school year progressed. For example, Andrew instructed onehalf of the children on the skill theme of dribbling while Amanda taught gymnastics to the other children. After the period or unit of instruction was completed, the groups of children were "flip-flopped".

Amanda was responsible for teaching the curricular unit which focused on fitness-related concepts. During this unit, students were introduced to cognitive concepts specific to the components of health-related and skill-related physical fitness and participated in physical activities which focused on these components. The fitness concepts presented in this unit were then revisited during relevant experiences in other instructional units in the physical education curriculum.

Physical fitness tests, given in the Fall (usually October) and Spring (April) of each year, were used to complement the teaching of these concepts of fitness and helped to provide students with an understanding of their personal fitness levels. Both teachers assisted in administration of the test items. Computerized test results were presented to each student and helped them in setting physical fitness goals according to their strengths and weaknesses. In addition, students received fitness "homework" on calendars throughout the year (see Appendix A), as well as other fitness-related worksheets and information which stressed fitness knowledge and activity. Students were able to return this homework to school, where it might be posted in the physical education complex. Much of this information which was sent 
home was also aimed at informing parents about fitness and activity habits relative to their child.

\section{$\underline{\text { School B }}$}

School B is in a predominantly urban area and had three full-time teachers for grades K-5 at the time of this study. The teachers, "Barbara", "Bradley", and "Betty", had taught elementary school physical education for 15, 25, and 11 years, respectively at the time this study was conducted. Children at this school normally received 30 minutes of daily physical education instruction from the same teacher throughout the year.

Physical fitness testing also took place at School B twice a year, usually in September/October and March/April. Each physical education teacher administered the same test item(s) to all students in the school in both the Fall and Spring, to assure consistency in testing procedures and results. Students did not receive computerized test results on their performances such as was given at School A.

There was no separate unit of instruction for fitness-related concepts by teachers at School B such as was done at School A, although teachers at School B did present students with some concepts of fitness at relevant times during the school year. The only time fitness concepts alone might be the focus of the day's lesson was in instances when a "rainy day" would force students and teachers into the indoor classroom allotted for physical education. During these times (which were rare), a filmstrip related to fitness might be shown. 
Being physically active was stressed at School B through a take-home program called "Keep On Moving". In this program, students were encouraged to "keep on moving" for at least 30 minutes after school; if they did, they wrote down what they did on a piece of paper, had their parents sign it, and then returned it to the physical education teachers. Once a week, a name was pulled out of all received entries, with the "winner" receiving a "Keep On Moving" t-shirt.

Students at School B took part in a county-wide "fitness meet", in which students from different schools met during the school day and competed in the different physical fitness test items. Students who were chosen to go to the meet (based upon their test scores) were usually picked from grades 4 and 5 .

\section{$\underline{\text { Subjects }}$}

The subjects for this study were fourth and fifth grade students at both School A and School B. To be considered part of the "pool" from which subjects were chosen, students had to return a signed parent permission letter (see Appendix B) (given out by the teachers the week before the scheduled interviews). They also had to have completed the physical fitness test in the past fall at their present school.

Because this study sought to look at any possible differences between students who performed poorly and well on the fitness tests as a whole, a special effort was made, whenever possible, to interview students who tended to score either "poorly", or "well", on the fitness test items which were given the previous fall (see Chapter 1 for operational definitions). 
An interview schedule listing the children to be interviewed on each specific day was organized prior to data collection. As mentioned earlier, when possible, two students who scored either "poorly", or two who scored "well", were chosen at random to be interviewed together during each class period. In the case this was not possible, either due to a lack of students classified at either of these levels, a child not wishing to be interviewed, or a child scheduled for interviewing being absent from school that day, then one or two other students whose scores were ranked in the "average" category were chosen at random from those eligible to be interviewed.

\section{$\underline{\text { Design }}$}

The type of research which was primarily used to conduct this research study was that of a qualitative nature. Also called "interpretive" or "naturalistic" research (Locke, 1989) this study used the interviewing process as a primary means of determining the underlying thoughts and feelings of subjects which are not accessible through other forms of research. By interviewing children at each school, the subtle differences which a questionnaire or an observation of behaviors, for example, would not be able to uncover could be discovered and examined in relation to the particular setting. In addition, participant observations, informal interviews with other subjects, and field notes also served as a means of collecting data at each site.

A secondary data source used in this study was a written test which focused on the students' understanding of various cognitive aspects of the physical fitness 
tests. This quantitative data was corrected and analyzed according to the procedures outlined in the Data Analysis section, found later in this chapter.

\section{$\underline{\text { Procedures }}$}

The following section details the procedures which were used to collect and analyze data during this study.

\section{Data Collection}

Data was collected from five different sources: students, physical education teachers, principals, classroom teachers, and the county physical education supervisor. The different methods used for the collection of data from each of these sources are presented below.

\section{$\underline{\text { Students }}$}

All students took a written test during their physical education class (see Appendix C) on the first scheduled day of data collection. At both schools, the quiz was given on a Monday; interviews were held during the following four school days. It was hoped that this test would reflect the knowledge students possessed regarding the physical fitness tests and would provide some preliminary information for the interviews.

The test was administered to students at both schools while they were gathered on the floor in the indoor area used for physical education during inclement weather. Paper and pencils were provided to students (although some classes of students at School B brought their own). After the physical education teacher had 
introduced the researcher as someone who was interested in finding out what they thought and knew about the physical fitness tests, the teacher left the room. It was explained to students that the quiz they would take consisted of only five questions that would help me to understand what they knew about the tests. They were assured that this quiz had nothing to do with their physical education grade or report card, and that the researcher would be the only one to see their answers; they were also asked not to look at others' papers. If they weren't sure of a spelling, they were asked to do their best; if they didn't know the answer, they' were asked to write down "I'm not sure" or "I don't know". Students were then asked the five questions in the same exact way; the question was repeated one time. At the completion, papers were gathered and the students joined their physical education teachers. The only change that took place with this sequence happened with the last two classes of School B. After looking over the answers of the first two classes of students, it was noticed that none of the students knew the answer to question \#5, which asked them the purpose of the shuttle-run test. Out of curiosity, students in these two classes were asked to complete an "extra credit" question after the regular five, which was "which test measures your ability to change directions quickly?" (versus their "agility"). Papers were then gathered, as for the other classes.

The interviews themselves, which were conducted using a semi-structured protocol (Seda \& Pearson, 1991), took place during the children's regular physical education class period. At school A, these were conducted in an unused classroom 
near the physical education room which held only one table and a few chairs (both "sized for children") and was normally used for miscellaneous purposes at the school. At school B, interviews were conducted in an indoor area used by the physical education program during inclement weather. Interviews at school A took place either on the floor or while seated at the table, if so desired by the students being interviewed. At school B, interviews were conducted while sitting on carpet squares on the floor (no chairs or table were available).

Before each student was taken out of his or her physical education class to be interviewed, they were given a choice by the interviewer to be interviewed or not. In some cases, students did elect to stay in physical education and not be interviewed. At the beginning of each interview, students were told that their interview would be audiotaped, and were asked if this was all right by them. All students were also told at this point that what they said would not be told to anyone, including their physical education teacher. In addition, a point was made by the interviewer to let each student know that he or she would be able to leave the interview if they so wished, and that they didn't have to answer a question if they wished not to.

In all but one instance, the interview lasted no more than 30 minutes (the first interview at school A lasted approximately 8 minutes longer). When possible, two children who tended to score either "poorly", or "well", were interviewed together; this was to help each child feel more at ease and comfortable in the presence of both his or her peer and the interviewer. This procedure had been determined by the 
researcher as the most successful of a variety of interviewing situations set up during a pilot project conducted prior to this study.

Every effort was made during the data collection period to interview two students at each available class meeting. During two class meetings at School A, however, no students were able to be interviewed (AT3 and AF4), and at School B, there was one class time where no students were available to be interviewed (BR3) and two instances where only one student was able to be interviewed (BT3 and BW1). Because these two solo interviews did not follow the testing protocols, the data collected from these two interviews was not used during data analysis.

Student interviews were audiotaped for ease of later data analysis. Four guiding student interview questions, developed as a result of the pilot project mentioned above, were:

1. Did children understand the reason(s) why they took the physical fitness tests? Did they understand what the test items measured? Did they understand the implication of good, or poor, performance on the test items?

2. Did children understand how to improve their performances on each test item?

3. What did the children think, in general, about the physical fitness tests? Were they important to them? What did they like about them? Not like?

4. What did children think about their scores on the fitness tests? Did they think their parents felt their scores were important? 
5. Were there any differences in how students who tended to score well, versus poorly, responded to the above questions?

\section{$\underline{\text { Physical Education Teachers }}$}

The physical education teachers at each school were formally interviewed during the week the researcher was at their school. In most instances, this took place during the latter part of the week. These interviews were audiotaped and were conducted at the convenience of the teacher during the school day. They focused on the role of physical fitness concept instruction and the physical fitness tests in the physical education curriculum, the procedures used for test assessment, and the procedures used to let students receive feedback on their test results (see Guiding Questions, Appendix D). When possible, any written records teachers had showing the organization and planning of test concepts, procedures, and lessons were gathered. General background information relating to the teacher's experience was also discussed as part of the interview protocol.

\section{$\underline{\text { Principals }}$}

Each principal was formally interviewed during the week at his or her convenience. This audiotaped interview attempted to discover any insights the principal had regarding the physical fitness tests and testing at her or his school (see Appendix E for Guiding Questions).

\section{Classroom Teachers}

At each school, three classroom teachers of the students being interviewed 
(who were suggested by the principals) were formally interviewed to provide their insights about their student's reactions to the physical fitness tests (interviews were audiotaped; see Appendix F for Guiding Questions). It was hoped that additional insights about how students felt about the tests: their likes, dislikes, and fears might be described by the classroom teacher who spent the majority of the school day with the children. In addition, informal interviews with classroom teachers (during lunch, before school, etc.) were documented for purposes of subsequent analysis.

\section{Supervisor}

Finally, the county physical education supervisor was formally interviewed. His knowledge regarding the school, physical education programs, and philosophy of how the tests were used at each school was audiotaped and used to "triangulate", or validate, information gathered from the other four data sources. Again, see Appendix $\mathrm{G}$ for questions which guided this interview.

\section{Data Analysis}

Three sets of data gathered for purposes of this study needed to be analyzed. These included interviews, the written test, and supplementary documents.

\section{$\underline{\text { Interviews }}$}

The first set of data, audio-taped interviews of the subjects, comprised the largest amount of information gathered for this study. They were transcribed using ethnograph procedures outlined by researchers such as Bogden and Biklen (1982) and Erickson (1986). The computer program "The Ethnograph" (Siedel \& Clark, 
1984) was used so each line of the interview texts could be shortened and then numbered. The shortened line lengths and numbering of text facilitated the identifying and defining (or "coding") of the common, broad themes (i.e. "urging teacher behaviors", "embarrassment", "mile-run") which began to occur throughout the data. While the data was examined and "coded" according to these themes, some basic insights about "what the data was saying" was being made by the researcher. These insights were written down, along with other pertinent notes, and further analyzed during the reading and re-reading of data in order to more fully discern whether they were the most descriptive of what the data was saying.

Once all the interviews were "coded" according to the broad themes mentioned above, the data was then "cut and pasted" onto the pages of a large artist's sketch pad under each of these themes, similar to a process followed by Graham, Hopple, Manross, and Sitzman (1993). This allowed for an overall, easy to access view of the data which was relevant to each assertion. If a passage was coded according to more than one theme, it was photocopied and pasted under each theme.

Once this cutting and pasting process was complete, data from each theme was further examined in order to either confirm, disconfirm, or combine prior insights about the data (or even, to form new ones). The resulting "assertions" were considered most representative of what the data was saying; if needed, data from different themes which supported or negated a specific assertion was then recut-andpasted so it was physically in one place. At this point, the data under each assertion 
was ready to be used as a basis upon which the ensuing results chapter was based.

It should be noted that when analyzing data related to students' understanding of the purposes of the fitness test items, their responses were compared to those which the physical education teacher(s) at each school had given as the purpose for the particular test item (if, indeed, one was given at all). Thus, if a students' response did not reflect the explanation given for the test by his or her teacher, for purposes of this study, it was not "coded" as showing knowledge of the purpose of that particular test item. It is possible, however, that further interpretation of students' results, along with additional probing, may have revealed that some students possessed a greater degree of comprehension than was reflected by their original response. This may be indicative not necessarily of students' actual knowledge about the test item, but of their level of cognitive development. Note that when possible, the purpose of each test item, as given (and if given) by the teachers at each school is provided prior to the students' responses for that item.

Also, in an attempt to minimize any bias on the part of the researcher and to ensure that students' responses had been correctly interpreted during data analysis, an experienced elementary physical education specialist with expertise in the area of fitness was asked to review the analyzed data regarding students' understanding of the purposes of the tests as well as their additional responses. All questions raised by this expert were discussed with the researcher and revisions made, as necessary. 


\section{$\underline{\text { Written Test }}$}

The second set of data which was analyzed was the written test taken by each child. This test consisted of five questions designed to determine students' understanding of why they take the different fitness test items; in it, students were asked to name the test item which measured a specific component of fitness. The appropriate component of fitness which each test measured was taken from the testing program's literature; in addition, an elementary physical education specialist with expertise in the area of physical fitness was also asked to verify that each component of fitness indeed matched the test item which measured it.

Each item on the students' completed written quizzes were evaluated by the researcher to discern if it was a "correct" answer; some leeway was given at times in case a student misspelled an answer or described the test because they couldn't recall the test item name. Again, the same physical educator as mentioned above with expertise in fitness was given the students' written quizzes and asked to verify that the responses were indeed correctly scored as either "correct" or "incorrect". The percentage of correct answers for each test item was then determined for: 1) all students at school A and school B; 2) all students at both schools who scored well, poorly, and average on the tests; and 3) boys and girls at school A and school B, combined.

\section{Supplementary Data}

Lastly, the written lesson plans, curriculum outlines, field observations, and 
any additional information gathered were analyzed the same way as for the interview data. Evidence which confirmed or disconfirmed the assertions were integrated with the other data onto the "sketch pads", therefore allowing for the support and validation of information already analyzed.

\section{$\underline{\text { Summary }}$}

This study used interviewing as the primary method of determining what children, especially those who tended to score poorly, and well, thought, felt, and knew about the physical fitness test and test items. The subjects were children in grades four and five at two different elementary schools in the same school district in a large southeastern state. In addition to the interviewing of children, physical education teachers, principals, classroom teachers, and the county supervisor of physical education were included as a source of data. Analysis of data involved the transcription of the interviews according to ethnographic procedures and the subsequent formulation of assertions which described the common themes, similarities, and differences supported through the collected data. A written test was also used as a method of determining the knowledge children have regarding the physical fitness tests and test items. 


\section{CHAPTER IV}

\section{Results and Discussion}

Throughout the process of reading the many interviews which were a part of this study, eight assertions, organized under five categories, emerged from the data analysis. After additional analysis, these assertions were then refined. The categories and assertions that are used to organize the results are:

\section{Category: Student Understanding}

Assertion 1) Most students do not have a clear understanding of why they take the physical fitness tests;

Assertion 2) Students feel the best way to improve their performance on a test item is to replicate the test at home;

\section{Category: Teacher Behaviors}

Assertion 3) The urging or encouraging teacher behaviors exhibited by teachers during the test taking process make an impact upon students;

\section{Category: Students' Feelings}

Assertion 4) Many students who perform poorly on the test items receive negative feedback from peers in the form of ridicule and public embarrassment; Assertion 5) The ritual of receiving and comparing scores holds different meaning for those who perform well, and poorly, on the tests; 


\section{Category: Parental Involvement}

Assertion 6) Children who score well on the tests tend to talk more, and differently, about their parent's interest and involvement in their fitness scores and activity habits than those who tend to score poorly;

\section{Category: Mile-run Test}

Assertion 7) Many students dislike taking the mile-run test, some so much that they become "test dodgers";

Assertion 8) Given the chance, many students would change the mile-run to make it more fun.

While separated above for clarity, each of the above categories and assertions are intricately connected in the real world of the elementary physical education class. Each is important, for they seem to impact upon the picture of physical fitness testing which children paint in their minds as a result of their physical education experiences. To more fully describe this picture, each of the above eight assertions are presented and described below. Data taken from the children's interviews, in part, are used to support each of the assertions. In addition, a discussion of these results is presented at the end of the chapter.

\section{Category: Students' Understanding}

\section{Assertion One: Most students do not have a complete understanding of why they take the physical fitness tests}

Thousands of children across the country take a standardized physical fitness 
test once or twice during each of their elementary school years. It is possible, then, that a student has taken a standardized physical fitness test on at least eight different occasions by the time he or she begins fifth grade. As such, it becomes interesting to find out whether or not students really understand why they are taking these tests. This is one of the main questions this study sought to discover.

In this results section, students' understanding about the purpose of the physical fitness test is broken down into two different sections: the first relating to their understanding of the tests in general, and the second relating to their understanding of each specific test item.

\section{Understanding: In General}

Why do teachers say the students take the physical fitness tests, in general? Amanda says it's "mainly to see if our program is helping to improve their (students') fitness levels, also so they can see how they're doing fitness-wise" (ATCHRAMA, 248-255). Is this the same reason students think they take the tests? To find out, students were asked the questions, "why do the teachers have you take these tests" and "is it important for you to take these tests?" during the interviews. Here are a few statements, taken from student interviews, which show an understanding of why students took the tests:

Maria: "They (teachers) just want to see if their programs could work" (AT4.3, 158-159).

Randy: (We take them so) "We can see how physically fit we are" (BF3.1, 
37-38).

David: "If we didn't have the tests, we wouldn't know really how...healthy you were" (AR3.2, 54-56).

Wanda: "Well, it tells them (teachers) how good your body's fit" (BW3.6, 283-284).

Jeremy: "If we are or we aren't physically fit" (AT1.12).

Unfortunately, not all students in this study had as complete an understanding as Maria, Randy, David, Wanda, and Jeremy as to why they were taking the physical fitness tests. Most students asked showed an incomplete understanding, just plain didn't know, or held what seemed to be misconceptions about why they were taking these tests. These thoughts are outlined below in six different categories: getting and staying in shape, for their future health and life, going to the fitness meet, just don't know, to be an athlete, and grades.

\section{Getting or Staying in Shape}

One of the more common thoughts students seemed to hold about taking the tests was that they were given the tests so they could get, or stay, in shape. Many gave responses similar to Mia's, when she says: "They're to get you fit...physically fit...to get more energy" (BT2.4, 219-220). Mary (BT1.5) feels she takes the tests "(to) Keep you in shape"; Evelyn (AW4.4) says they're "So we can make our muscles stronger" (209-213). Hillary feels "They're getting you in shape" (AF3.2, 91-92); Kendra (BF1) thinks they are to "Help you run and help you build muscles" 
(74-75). Hallie (BT2.5) thinks they're so "Maybe just like in the morning if you want to play, you can play, or if you want to get out and run you can run" (223225). As another example, Cathy (AT4.4) says the tests are important "So we can get better".

$\mathrm{CH}$ : So what gets better?

C: So our muscles get better. (207-208)

Too, Sally thinks they aren't important "Cause we get fitness every day from home" (AR1.2, 69).

\section{For their future health and life}

Some students also talked about the purpose of the tests in terms of their overall future health and fitness. For example, Susan thinks she and her classmates take the tests "So we won't grow up to be really scrawny and sick" (AW4.8, 404405); Harriet (AW3.3) thinks it's so "We don't get fat, so we stay nice and healthy...so we don't get cancer" (120-122). Sandy follows with "So when we grow up, they (teachers) can't say, we didn't teach you, and you know how to take care of yourself...they kinda' give us an image of what we look like in the future". That this is important to her is shown when she also says "I think that when I grow up, at this age, you're really just starting to develop your bones and all that, and if I work on it now, and I start to take care of myself now, I always have the thought that I'll be pretty, and fun, when I grow up" (AT1.10). 


\section{Going to the Fitness Meet}

Some students at school B thought they took the tests to find out who goes to the "physical fitness meet" which they and other schools in the district participate in, as Karen testifies below:

Well, we take the tests...it sees how good you can do these things, some people that are good, up on that board (bulletin board in the room), they get to go to a fitness meet, and they go against other schools. (BW3.1, 22-28) Cailey and Rosie (BT4.3) are probed further in their response:

$\mathrm{CH}$ : So the reason you do these is to see who goes to that...what is that called?

Both: The fitness meet.

$\mathrm{CH}$ : Is that the reason you take those?

Both: Yeah. (110-114)

Trace (BF2) relates "It doesn't concern me that much (the test) except, that, like, I try to get to the meets, and that's the only reason that I try to do these tests as best as I can...to try and get to the meets" (185-189).

\section{$\underline{\text { Just Don't Know }}$}

Some students didn't know why or just weren't sure why they took the tests; in many cases this showed through in their reasoning of why the tests were (or weren't!) important. For example, when Jarod (BR1.2) is asked "Is it important for you to take these, you think" he flatly answers "No". When asked to explain his 
answer further, he says "I don't know...I really don't know, I just don't think they're important" (64-65; 80-82); Carrie also says "I don't know" (BR2.8, 400). Mary (BT1.9) thinks "I don't think it's (the tests) really important...I think keeping healthy is, but I think there's a little more important, getting a good education and working, so you don't die or anything" (470-488). Jeremy (AT1) thinks "I think they (the teachers) think it's important for us to know that we're beating (their goals), that we're actually doing it (the tests) right". Trina (BF4.8) gives her opinion when she says

See, all these tests are really good tests, if you want to be physically fit for the rest of your life you can do all these things, to make sure you're the best and everything, but to me, I don't want to be the best at all those...I don't think in further use I'm going to go to my next job and at my job interview I'm going to go, I can do 50 situps, watch! (425-439)

\section{To be an athlete}

To other students, the tests improve their fitness for sports they will play in later life, as shown by Hallie: "They kinda make you physical, if you want to be a world champ in the Olympics or something. Really fit,...kinda just skinny!" (BT2.1, 30-33) and Mitch "(they're important) Because I want to grow up to be like a track star or either play baseball" (BR1.2, 70-71). Karen (AF2.4) feels they're important "If you're going to be like a runner, or ballet dancer, or something". 


\section{$\underline{\text { Grades }}$}

And finally, a few students think they are important for another reason: grades. For example, Rupert feels that the tests are important "Because...they're going to let me pass".

$\mathrm{CH}$ : Pass what?

R: Fifth grade. (AR2.4, 187-192)

Carrie agrees, saying "They are (important) to me, because I'm worried about my grades, because I'm on (safety) patrol" (BR2.4, 217-219); David concurs by saying "Yeah, because we have these things that go home in our report card" (AR3.4, 190192).

\section{Understanding: Specific Test Items}

Through the interviewing process, teachers at schools A and B described each specific fitness test item as a way of determining students' levels of a health-related fitness component (i.e. cardiorespiratory functioning, muscular strength and endurance, or flexibility). Therefore, it seemed appropriate to find out if students also understood the purpose of the five test components.

Both a short written quiz and student interviews were used as a means of determining students' understanding about individual test items. Results from the written quiz are first presented below; following this, data from the interviews will be presented according to each specific test item (i.e. the mile-run, sit-and-reach, curl-ups, pull-ups, and shuttle run tests). 


\section{$\underline{\text { Written Quiz }}$}

The results from the written quiz were analyzed in order to gain a more accurate picture of whether students understood what component of health or skillrelated fitness each fitness test item measured. They helped to answer questions such as, did students actually understand that the mile-run was used to measure their cardiorespiratory endurance, and that the sit-and-reach was used to test their lower back and hamstring flexibility? Did they realize that pull-ups were used to determine their upper arm and shoulder girdle strength; curl-ups, their abdominal muscle strength and endurance; and the shuttle-run, their agility?

Analyzing the written quiz involved looking at how students at school A scored versus those at school $\mathrm{B}$, and if there were differences between the results of boys and girls and those who tended to score poorly, well, and average on the tests. Each of these categories will be explained below in greater detail.

School A vs. School B.

In looking at the quiz results of students at schools A and B it became readily apparent that students at school A seemed to have a greater understanding of why they took each specific test item, as compared to students at school B (see Table 1). There is a clear trend showing that over half the students at school A were able to recognize which component of fitness each test item measured, and that generally less than half of the students at school B were able to do this. The greatest discrepancy can be seen for the mile-run test; whereas $70 \%$ of all students at school 
Table 1. All students - School A vs. School B

$\underline{\text { School A }}$

(\% correct)

$$
\mathrm{n}=155
$$

$70 \%$

57

79

74

61 $\underline{\text { School B }}$

$\mathrm{n}=215$

$29 \%$

36

56

74

47 
A knew that this test measured their cardiorespiratory fitness, only $29 \%$ of students at school B were able to recognize that this health-related component of fitness measured this test item.

Students Categorized by Fitness Test Performance

In looking at the results of how students scored on the quiz according to their category of performance on the test items, it can be clearly seen that those who performed well, and average, on the tests tended to score better on the quiz than those students who performed poorly on the fitness test items (see Table 2). One could also say that students who tended to perform well on the tests scored very similarly to those who performed average on the tests.

When one looks at these different categories of students in terms of school A versus school $\mathrm{B}$, one can see from Table 3 that there is a definite trend for all students at school A, no matter what his or her performance on the test items, to score better on the written quiz than students at school B. If one looks at how students in the different categories scored at their respective schools, it can be seen that students in all three categories of test performance seemed to score similarly on the written quiz.

In Table 4, one can see how only those students who were interviewed (versus all students) scored on the written quiz (see Table 4). Again, these students were categorized according to their performance on the test items, as well as by school. Results show that students who tended to score well, and average, on the test 
Table 2. All Students by Test Scores

\begin{tabular}{lll}
$\underline{\text { Students with }}$ & \multicolumn{1}{c}{ Students with } & $\underline{\text { Students with }}$ \\
Lower Scores & $\underline{\text { Higher Scores }}$ & "Average" Scores \\
$\mathrm{n}=103$ & $\mathrm{n}=86$ & $\mathrm{n}=109$ \\
& & \\
& $(\%$ correct $)$ & \\
$34 \%$ & $47 \%$ & $61 \%$ \\
35 & 52 & 55 \\
52 & 76 & 72 \\
70 & 83 & 81 \\
44 & 62 & 58
\end{tabular}


Table 3. All Students By Scores and By School

\section{$\underline{\text { School A }} \quad \underline{\text { School B }}$}

Students with Lower Scores $\quad n=25 \quad$ (\% correct) $\quad n=78$

$\begin{array}{lll}\text { 1. (mile-run) } & 72 \% & 22 \%\end{array}$

2. (curl-ups) $72 \quad 32$

3. (sit-and-reach) $60 \quad 49$

$\begin{array}{lll}\text { 4. (pull-ups) } & 72 & 81\end{array}$

5. (shuttle-run) $\quad 44 \quad 44$

$\begin{array}{lll}\text { Students with Higher Scores } & \mathrm{n}=30 & \mathrm{n}=56\end{array}$

$\begin{array}{lll}\text { 1. (mile-run) } & 79 \% & 30 \%\end{array}$

2. (curl-ups) $\quad 77 \quad 39$

3. (sit-and-reach) $\quad 93 \quad 48$

$\begin{array}{lll}\text { 4. (pull-ups) } & 90 & 79\end{array}$

5. (shuttle-run) $73 \quad 55$

$\begin{array}{lll}\text { Students with "Average" Scores } & \mathrm{n}=55 & \mathrm{n}=54\end{array}$

$\begin{array}{lll}\text { 1. (mile-run) } & 78 \% & 43 \%\end{array}$

2. (curl-ups) $\quad 69 \quad 41$

3. (sit-and-reach) $\quad 82 \quad 61$

$\begin{array}{lll}\text { 4. (pull-ups) } & 87 & 74\end{array}$

5. (shuttle-run) $\quad 71 \quad 44$ 
Table 4. Interviewed Students with Lower vs. Higher Test Scores

$\underline{\text { School A }}$

Students with Lower Scores

1. (mile-run)

2. (curl-ups)

3. (sit-and-reach)

4. (pull-ups)

5. (shuttle-run)

$\underline{\text { Students with Higher Scores }}$

1. (mile-run)

2. (curl-ups)

3. (sit-and-reach)

4. (pull-ups)

5. (shuttle-run)

$\underline{\text { Students with "Average" Scores }}$

1. (mile-run)

2. (curl-ups)

3. (sit-and-reach)

4. (pull-ups)

5. (shuttle-run) $\mathrm{n}=4 \quad(\%$ correct $)$

$100 \%$

75

100

100

100

$\mathrm{n}=10$

$80 \%$

$70 \%$

$90 \%$

$80 \%$

$70 \%$

$\mathrm{n}=6$

$83 \%$

$83 \%$

$83 \%$

$83 \%$

$100 \%$ $\underline{\text { School B }}$

$\mathrm{n}=13$

$39 \%$

39

39

69

46

$\mathrm{n}=8$

$75 \%$

$63 \%$

$88 \%$

$100 \%$

$75 \%$

$n=6$

$67 \%$

$50 \%$

$83 \%$

$83 \%$

$83 \%$ 
Table 5. All Boys vs. Girls -- Both Schools

Boys

(\% correct)

$\mathrm{n}=179$

$43 \%$

41

56

75

46 $\underline{\text { Girls }}$

$\mathrm{n}=176$

$47 \%$

46

73

77

57 
Table 6. All Boys vs. Girls - by School

\begin{tabular}{|c|c|c|}
\hline & School A & School B \\
\hline & Boys & Boys \\
\hline & \multicolumn{2}{|c|}{ ( $\%$ correct $)$} \\
\hline & $\mathrm{n}=70$ & $n=109$ \\
\hline 1. (mile-run) & $67 \%$ & $28 \%$ \\
\hline 2. (curl-ups) & 50 & 36 \\
\hline 3. (sit-and-reach) & 71 & 47 \\
\hline 4. (pull-ups) & 76 & 75 \\
\hline \multirow[t]{4}{*}{ 5. (shuttle run) } & 49 & 45 \\
\hline & $\underline{\text { Girls }}$ & $\underline{\text { Girls }}$ \\
\hline & \multicolumn{2}{|c|}{ (\% correct) } \\
\hline & $\mathrm{n}=70$ & $n=106$ \\
\hline 1. (mile-run) & $71 \%$ & $30 \%$ \\
\hline 2. (curl-ups) & 60 & 36 \\
\hline 3. (sit-and-reach) & 84 & 66 \\
\hline 4. (pull-ups) & 83 & 74 \\
\hline 5. (shuttle-run) & 70 & 49 \\
\hline
\end{tabular}


items tended to score almost identically at both schools A and B. Only for the category of those interviewed students who tended to score poorly on the tests was there a clear difference; here, students who scored poorly at school A were better able to recognize which component of fitness each test measured than their counterparts at school B.

Boys versus Girls

Table 5 shows the difference between how all boys (at both schools) scored on the written quiz when compared to girls at both schools' (see Table 5). It can be seen that girls, in general, tended to score slightly higher than the boys, although the difference was not very great.

Table 6 then looks at how boys at school A scored on the quiz versus boys at school B, and likewise for the girls. It can be seen that boys at school A tended to score better on the quiz than boys at school B on all five quiz items (see Table 6). For girls at schools A and B, the results were the same: girls at school A scored higher on all five quiz items than girls at school B. Interestingly, girls at school A tended to score quite a bit better than girls at school B whereas the boys at both schools tended to score closer together. Also, one can compare from Table 6 how girls at school A scored versus girls at school B and likewise for the boys; again, girls at both schools tended to score just slightly higher than the boys at their respective school.

In summary, when analyzing the quiz results, it is apparent that students at 
school A tended to score better than students at school B. This shows that students at school A were generally able to recognize which component of fitness each test item measured. There was a slight, but not overall, trend for students who performed well on the test items to score higher on the quiz than students who performed poorly on the test items. Girls at either school tended to score higher on the quiz than their male counterparts, although again, the margin of difference was small.

\section{Interviews}

Interviews with students were able to offer additional insights as to what students knew about the physical fitness tests beyond the pencil and paper quiz. In the interviews, students were asked the purpose of the five physical fitness test items. Their responses are organized below under the specific test items in the order of the mile-run, sit-and-reach, pull-ups, curl-ups, and shuttle-run.

\section{Mile-run}

The generally accepted purpose of the mile-run test is to determine students' level of cardiorespiratory functioning. At school "A", students were instructed by Amanda that the concept of "cardiovascular" is "Improving your heart and your blood vessels and improving the capacity of your heart to pump the blood through your body to bring oxygen to their muscles so the muscles can do their work" (ATCHRAMA, 176-184). Andrew, at the same school, says that he tells students that "Running the mile is a good way of measuring your cardiovascular fitness" (ATCHRANW, 126-134). 
At school "B", Barbara says that the one thing that students at her school should know about the mile-run test is that it "Is an endurance run...we don't talk about cardiorespiratory; we just talk about how healthy and strong their lungs are" (BTCHRBAR, 120-122). During the year, she says, "We mention more endurance type activities -- aerobic activities (160-164). This means they should move for 30 minutes without stopping" (184). Bradley says the words he uses with students which relate to the mile-run are "It makes your heart stronger...it's going to build up your heart" (BTCHRBRA, 40-47).

When discussing the reason they took the test, or why it was important, many students used the terms described by their teachers and were often able to show their comprehension by using their own words. For example, Joshua shows an understanding of the term "endurance" when he says:

(C: Why do you take that? [mile-run]?)

$\mathrm{J}$ : To see your endurance.

C: Endurance of what?

$\mathrm{J}$ : Of how long we can stay running...without stopping. (BW2.2, 92-97)

In another example, Trace and Denver together explain:

C: Why do the coaches have you take the mile-run?

T: It tests your endurance.

D: And your respiratorial system, or whatever. 
C: What is your endurance? What does that mean?

D: Endurance is I think is how hard you run it, like if you don't sit down and start walking, that's not much endurance, but if you keep on running and try your best, then at the end you start running as fast as you can, and that's your endurance, I think. (BF2.3, 147-161)

Billy, at the same school, says the reason for taking the mile-run is to "See how good of shape your heart is in". When asked who tells him that, Billy replies:

"Coach" (BR4.2, 72-77). Rupert, at school A, says the reason is for "Cardiovascular...something". When asked what this means, he says: "Well, we're really trying to run it and see if I can run it without walking" (AR2.2, 57-68). Jarod and Mitch (BR1.2), in the same interview, share this:

C: Why do you take the mile-run for? Why do the teachers...

$\mathrm{J}$ : Lungs and heart.

C: What about them?

M: To see if they're working properly, and good. (83-89)

Mary and Roberta (BR1.2) say the mile-run is to "See how good your heart is...and your lungs" (90-91); Billy says simply, "To see how good of shape your heart is in" (BR4.2, 71-74).

Even though some students did show an understanding of why they took the mile-run test, many of the students interviewed appeared to have an incomplete, concrete (vs. abstract) understanding of why they took the mile-run test, when 
compared to the purpose given by the teachers. For example, although some students were able to associate a word which the teacher gave them with the test (i.e. cardiorespiratory fitness), further prompting would show that they don't fully comprehend what this term means. For example, Robert (AF2.4) says "We have to do the mile".

C: You do? Why do you do that?

R: Cardiovascular system.

C: What's that about? What does that mean?

R: I guess improving your heart rate. (42-51)

Norbert (AR2.2) relates that the mile-run test is for "cardiovascular health...I don't know what it is...just cardiovascular" (60-62). Other students had no idea about why they took the test; Rupert (AR2.3) says, "the only reason we do the mile run is to get a time, and if you...you can miss all the other tests, but you have to make the mile run a pass" (134-138). Bella (BF1.1) says simply, as to the reason they take the test "I don't know" (98-99); this was a response which was shared by a few other students, as well. Some students felt that the reason they took the test was to get them in better shape. For example, Karen says the coaches have them take the milerun test "just to get us exercising most of the time" (BW3.1, 45-48). Trina (BF4.4) says it is to "build up our stamina" (175); Mia thinks it's to "get in shape...see if you're going to be in shape when you grow up" (BT2.7, 353-357). From a different perspective, Wanda says the mile-run is to find out "how good your heart is, and if 
you're bleeding enough when you run" (BW3, 207-208). (Although this is certainly not correct in terms of the explanation for the mile-run given by her teacher, Wanda's explanation does reflect the concrete level of thinking common to many children her age.)

At school "B", some students also have the opportunity to go to a multischool "track meet"; students are chosen to go based on their scores on the physical fitness tests. Mia (BT2.3) says the reason they do the mile-run is to "see who's going to be in the track meet, and stuff" (126-127).

In summary, although some students seemed to understand why they took the mile-run test, it was apparent that many students did not show a complete understanding, or had no idea, of why they took this particular test item. This was also the conclusion gained from asking students about the next test item, that of the sit-and-reach test.

\section{Sit-and-Reach}

The generally accepted purpose of the sit-and-reach test is to test the flexibility, or ability to stretch, one's lower back and hamstring muscles. At school "A", Amanda relates the term "flexibility" to "stretching your muscles...mainly, for the test, your muscles in your lower back and the upper back of your legs" (ATCHRAMA, 196-199). At school "B", Barbara says that they relate the sit-andreach with "how flexible their back is; their legs and back are" (BTCHRBAR, 120126). Also at school "B", Bradley says that the sit-and-reach "is going to help stretch 
your muscles, to where you'll be able to reach forward...we don't get real technical with them" (BTCHRBRA, 48-51).

When analyzing students' answers for the sit-and-reach test, only a few students showed complete comprehension of it's purpose. For example, Carrie (BR2.9) says "I think they do it for flexibility...to see how flexible you are".

C: What does that mean? What does flexibility mean?

$\mathrm{K}$ : How easy you can move in different directions...something like that. $(448-454)$

Denver (BF2.2), says the test "Shows you how flexible you are". When asked if this is good, he explains further, "Yeah, then it means you are fit...if you can like bend and do a lot of that stuff, then you know you're fit, and you've been exercising, and stretching" (110-120). Darla and Katherine (AF1.1) explain the purpose of the sitand-reach test this way:

D: ...You have to see how many centimeters you can reach

K: For flexibility

C: What's flexibility?

K: It's how much you can stretch, and how far, like if you can do a split or something. (32-40)

Trina says that flexibility means "How far you can like, how stretchable you are...like if you can reach your toes, that's pretty good" (BF4.2, 98-100). And Joshua and Skyler (BW2.2) relate that one takes the sit-and-reach test: 
S: To see how flexible you are.

$\mathrm{J}$ : Your legs

C: What does that mean, if you're flexible?

$\mathrm{J}$ : Like if your movement isn't limited that much. (62-68)

Not all students had the same understanding as to why they took the sit-and-reach test; most students interviewed had either a partial or no understanding of what the purpose of the sit-and-reach test was. Many times, these students were able to relate it to the word "flexibility", or to one's back and legs, but were not able to give further correct information about it when prompted. Or, they were able to relate the test to "stretching" or "reaching", but weren't able to define this in relation to the term flexibility. For example, Chrissy (AF3.1) knows that you take the test to "Find out your flexibility", but when questioned further, she says this is "About your muscles...it helps you get stronger in your arms" (29-32). Karen (BW3.2) says that flexibility "Is when you can do a lot more things than other people...I know a girl that's really flexible and she can put her feet behind her head" (123-127).

Other students think of flexibility only in terms of reaching or stretching with the sit-and-reach box, as Debbie (AW3.1) says, "It's telling you how flexible you are...how far you can reach, cause your legs go against this box that has a little ruler out there...so you can keep your hands together and you reach" (48-53). For others, they really had no idea about the purpose of the test; take Billy (BR4.2), who says it's to "See how much your arms have grew in the past year and months" (66-67). 
Cailey says it is "To see how far you can get" (BT4.1, 45); and Mitch (BR1.8) says simply "I don't know" (398). Sometimes students get the muscles which are being stretched mixed up, as in the case of Ellen (BR2.8) who says they take the test because "They (the teachers) want you to stretch, and it's mostly for your back and your stomach; they want the muscles in your stomach to be good, not sitting there..." (434-439).

In general, then, most students did not seem to show a complete understanding of why they took the sit-and-reach test item. This finding was slightly different for the next item, that of the pull-ups.

\section{Pull-Ups}

Pull-ups are given to students for the generally-accepted reason of measuring their upper arm and shoulder muscular strength and endurance. At school " $\mathrm{A}$ ", students were taught about the term "Muscle strength...in order to make your muscles stronger, you have to overload them...but not too much of that" (ATCHRAMA, 189-192) by Amanda. At school "B", Barbara talks about "How strong their arms are" for pull-ups (BTCHRBAR, 118-119) and Bradley says they are for "Building up your arm muscles, your strength, for your pullups" (BTCHRBRA, 56-59).

In analyzing students' responses, it quickly became apparent that answers were centered around two opposite levels of understanding: either students fully - or didn't at all- understand the reason for taking this test item, in relation to the 
purposes given by their teacher. It was positive to see that a greater number of students seemed to understand that the reason for the pull-ups test was to measure their arm strength than those who did not.

For example, when asked why they take this test, it was common for students to answer as Trace (BF2.4) did: "The pullups test how strong your arms are...(like, if you can hold up your body weight)" (210-213); David (AR3.1) says they are to "Test how good our muscles are in our arms" (43-44); Leah (BW4.1) says they are "To see how strong your arm muscles are" (32). Less common was Katherine's also correct response (AF1.1) that "I think it's muscular strength...and muscular endurance, because you have to keep trying" (22-26).

Some students, however, either didn't know the reason as to why they took this test, or they thought the reason for taking the tests was to build their strength, not measure it. Again, while not necessarily incorrect, these responses did not completely reflect their teacher's said purpose of the test. For example, Robert (AF2.2) says the test "(it is to) Strengthen your upper body" (56). This response was shared by a few other students, as well; Kendra says the pull-ups "Help you build muscles and carry things heavy and stuff" (BF1.6, 316-318); Laura says they're to "Build up your muscles" (AR1.2,62). Skyler (BW2.3) says "Well, the pullups here, don't ask me anything about it cause I don't know anything about it"; he goes on to say they are important only if "You're a boxer or something" (183-184).

In summary, many students -- as for the previous two test items -- did not 
show a complete understanding of the reason why they took the pull-ups fitness test item. Perhaps because of the specificity of this test to the work of one's arm muscles, more students, however, did seem to show a complete understanding of the reason for taking this test when compared to the other test items. One of these included the curl-ups test item, for which results are described next.

Curl-ups

The generally accepted purpose of the curl-ups test is to determine one's level of abdominal strength and endurance. At school "A", Amanda says "The reason you're doing curlups is to test your abdominal strength" (ATCHAND, 146148). At school "B", Barbara says curl-ups are to test "How strong your stomach muscles are" (BTCHRBAR, 117-118).

As an example of a student who might understand the purpose of this test item, Denver (BF2.4) says they "Measure your stomach strength and the endurance in your stomach to see if you can keep lifting yourself up, back and forth and back and forth, up and down, until the time you have to do it is over" (219-224). Most students, however, were not able to completely define the purpose of the test. These students may have been able to relate the curl-ups test to their abdominal (or stomach) muscles, but were not able to explain anything further about them; or, they thought that the purpose of taking the curl-ups test was to strengthen, rather than test, their abdominal muscles.

As examples, Karen (BW3.4) says the test is for "Stomach muscles", but 
cannot explain anything more about them (176). Darla and Katherine (AF1.4) can relate the test to "Abdominal muscles", and go on to further explain the whole test, but cannot further explain what about their abdominal muscles is relevant (173). Liza (BF4.8) says about them "You use your stomach muscles more than anything... that's just strengthening your stomach muscles" (412-415); Hallie (BT2.3) says they take the test "For your stomach, too, because it tightens up your stomach" (115-116). And Susan (AW4.4) says "It helps your back muscles, I think...your back and stomach muscles" (203-205). Jarod (BR1.3) thinks this test is important not so one can determine one's abdominal muscle strength and endurance, but rather "Well, if you grow up to be a boxer and you get hit in the stomach a lot" (119-120).

In summary, then, most students did not seem to have a full understanding of why they took the curl-ups physical fitness test item. This trend was furthered by the insights shared by students regarding the shuttle-run, which is detailed next.

\section{Shuttle-Run}

The shuttle-run has historically been given as a test to determine one's agility, or ability to change directions quickly. Although this is a skill-related, rather than health-related, fitness test, it is part of the district's fitness test procedures. At school "A", the test is explained as "Agility...being able to run, turn around without falling over, running into somebody" by Amanda (ATCHRAMA, 205-207). At school B, Barbara says the one thing that should stick in children's minds about the shuttle run is "Changing directions" (BTCHRBAR, 112-115). 
Some students were able to verbalize the above as the reason for taking this test item; for example, David says it's "To test our agility, and if you can change directions fast" (AR3.1, 27-29). Laura (AR1.2) says it's to "Test our turning skills" (58), and Darla (AF1.3) says it's for "Agility...it's when you change directions fast...a lot of the boys, I have to figure out when they're going to turn because I can't turn as sharp as they can, when I'm playing tag, I have to cut short, around curves" (146-158). At school B, Alicia says it's to "Show how fast you can run and how quick you can turn" (BF3.2, 88-89). Billy's answer is indicative of a few others when he says, "You start at this end, and you have to run down, and grab one, and take it back, and then go get the other one. And that measures how quick you can turn, and stop, and turn real fast" (BR4.3, 138-144).

As with other test items, though, most students seemed to not be able to fully explain why they took this particular test item. While students may have been able to associate the term "agility" with the shuttle-run test, they weren't able to always explain what it meant. For example, Tina (AT2.1) says "I think you call it for agility or something...I don't know these big words" (37-39). Karen and Robert try to explain agility; when asked what the term means, Karen laughs and says she doesn't know, while Robert says "A pace to go faster and slower" (AF2.2, 71-74). Harriet (AW3.2) thinks it's to "See how fast you can run, like in dashes or something" (7273); Cailey sees it's purpose "To see if you can run a short distance" (BT4.2, 8889). Wanda isn't sure when he says it's to see "How fast your reflexes are?" 
(BW3.4, 166). Jarod (BR1.3) says bluntly "There's no point in running and stopping, running and stopping", while in the same interview, Mitch feels "It's not really important for anything, unless you're a cop and you have to run real good" (147156).

In summary, then, even though some students were able to verbalize the reason for taking the shuttle-run test, many other students were not able to explain the reason why they took this test item.

\section{Summary: Student's Understanding}

One of the strengths of qualitative research is that it can be used to delve deeper and gain a richer understanding of topics that might otherwise go unnoticed if one was looking at purely quantitative results. An excellent example of this shown by the use of the written quiz in this study. If one looked at only the results of this quiz, it could be deduced that a significant number of students actually did understand why they were taking each specific test item. Only after also interviewing these students did questions arise as to how much students truly understood -- in contrast to the results of the quiz.

When looking at the overall level of understanding which students had about the test items, it appeared that most (but not all) students did not have a complete understanding of why they take the fitness tests and specific test items. Many times, students were able to recognize words or phrases learned from their teachers, but explained them in ways relative not to their teacher's explanations, but to the more 
concrete level of cognitive functioning that is typical of children at this age. At times, further probing was able to show that students did indeed comprehend the purpose for taking each test item.

In addition to discovering students' understanding of the purposes for taking the tests, it was also felt important to delve into their understanding of how to improve their performance on the different test items. The following assertion, then, completes the look into students' understanding about the tests.

\section{Assertion Two: Students feel that the best way to improve their performance on a test item is to replicate the test at home}

In trying to determine how much children understand about the physical fitness tests, it seemed appropriate to ask them not only if they knew why they were taking the tests, but also, if they knew how to improve their performance upon the different test items. To help discern this during the interviews, students were asked a question similar to "What if I didn't do very well on the (specific) test...what are some things I can do at home to get better on it"?

If they thought along the lines of Rupert when he says: "Well, you can think of what you're doing on the test, and what you're really being tested on, and you can find something else that uses those muscles" (AR2, 499-510), then one would expect that they might have an understanding of activities they could participate in that would help them improve their performance upon the test items. Through the 
analysis of the data, however, it also became apparent that most students felt the best way to improve on a test item was to replicate the test or the action of the test at home.

The idea that the tests themselves are used to improve one's performance on the test items is explored below first. Following this section, additional thoughts related to how students suggestions for improving the different test items are presented.

\section{Use of Test Items to Improve}

As mentioned above, it seems that students feel the best way to improve their test scores is to replicate the same fitness test at home. For example, on the milerun, the majority of students felt the best thing to do was, expectedly, to run at home: Hallie (BT2.7) thinks one should

Run the mile like (she) does, get really exercise and get skinnier, like me! Cause I'm pretty good...run the mile about twice, or if you just want to run it once, so you can everyday get skinnier and more fit, and do it better.

Wanda (BW3.1) says, "If you're bad at the mile-run, you should try to run at least the block or something" (33-37); Randy (BF3.3) says "You can try to build up your endurance by running a little bit every day, up and down your street a few times" (142-144). Darla and Katherine, in their interview, relate the following:

D: I did 11 minutes. 
$\mathrm{CH}$ : Is that a good score?

Both: Yeah

D: For me

K: For a girl.

D: Last time I did it, I did a 16 something. I've been practicing a lot.

$\mathrm{CH}$ : What do you do to practice?

D: I run every day...I stretch out at home, and we have this mile long trail in the woods behind us, where the people that live in our house before cut, and I run that every morning. (73-92)

Hallie (BT2.8) says "I'll run a mile in the morning so I'll get fit" (406-407); Rupert says "Just jog around and get used to it" (AR2.5, 236).

To improve upon the sit-and-reach, Harriet (AW3.7) says you "Try to do the same thing...you try to find a box, or a ruler, or even the carpet, and you try your hardest, and you keep trying and trying and trying. Each day you try to reach more to get a better grade...I should say a better goal" (373-39). David (AR3.3) says "You can make your own sit and reach at home, cause I have a sit and reach box" (111113), and Kendra (BF1.3) says "You could, every so often, you could try and put your legs out and touch your toes, and you could put your feet up against a wall, and try to reach and touch the wall and stuff" (130-134).

In much the same vein, students gave their advice for improving in the pullups. For example, Cathy says "I go to my swing, cause I have a swing, and it has a 
pullup bar" (AT4.7, 333-335). Evelyn (AW4.2) tells how "Sometimes when I go home, if I don't have any homework, I go outside and find a tree, and I do some pullups" (96-98). Wanda (BW3.11) relates "I'm not very good at the pull-ups, so my dad put a pull-up bar in the back of my house, cause I'm not very good, so I can start" (595-599).

Improving in the curl-ups follows much of the same pattern. Joshua (BW2.4) says someone, in order to improve, "Can just, if you have a clock, you can look and wait till the second hand is straight up, and practice curlups and see how many you can do" (217-221). Alicia says one should simply "Do curlups" (BF3.4, 203).

Although data regarding improvement for the shuttle-run was limited (due to time constraints during the interviews), Kendra's response is typical when she says "If you have a driveway at your house, you could put two things over here and do it" (BF1.3, 140-143).

\section{Improvement: Specific Tests}

Even though most students saw that replicating a test at home as the best way to improve their performance on a test item, some students did realize they could participate in other, different activities at home which would help improve the same aspect of fitness. This idea is explored in more detail below by presenting students' other suggestions of ways they could improve on the different tests. As you'll see, some of these are valid ways to improve, while others which just aren't quite correct. 


\section{Mile-run}

Of all the tests, the mile-run was the one which was easiest for students to describe alternative activities for improvement besides just running. For example, Wanda (BW3.4) says you can "Just, if you're watching TV and you're standing up and you're watching a TV show and you don't feel like sitting down, you could just sit there and jog in place" (195-199). Riding one's bike was mentioned by a few different students, as was "Race my dog and my sister, and I also play softball and I run the bases" (Kendra, BF1.3, 120-124). Skyler says he'll "Do like a lot of little things during the week, and the weekend we would really put a lot of pressure on exercising, and we would ride our bikes and play racquetball and play basketball, so it's not very fun if it's just my two sisters, but sometimes I call a friend or something" (368-377). In the same interview, Joshua says "Sometimes I practice without knowing it, like when I run and stuff, to go places" (383-384). Cailey says one could "Get good endurance, like go swimming a lot, run at your house to help get your endurance built up because it's a long ways" (BT4.5, 253-257).

\section{$\underline{\text { Sit-and-Reach }}$}

To help improve one's flexibility, students gave a few ideas; Catherine (BT4.9) said that one could "Stretch every morning" (478); Skyler, who is used to getting one of the highest scores on this test for his age, says "Well, I bend over, and let other people easily push me on the back, so I can bend and be more flexible" (BW2.7, 342-344). Carrie (BR2.9) says "I think just doing toe-touches...my Mom 
used to be able to keep her knees straight and put her hands flat on the ground, so you can keep practicing, and if you can do that, you're pretty flexible" (474-478). In the same interview, Ellen says "Just take exercise classes, where you're going in a dance class and you're sitting here, and you're sitting there stretching" (479-482). Katherine says "I stretch a lot at home because I like the sit-and-reach" (AF1.2, 8587), while Billy thinks that swimming can help one improve on the sit-and-reach; when asked why he thought this, he says "I don't know...I just, it seems right" (BR4.5, 241)..

\section{Pull-ups}

To help one improve the ability to do pull-ups, a common idea presented by students was to do "partner pull-ups" where one person lays flat, while a partner of equal weight stands over them, grasps them by the hands, and pulls them up. A few students answered like Mitch (BR1.6) when he says you could "You know those little hand weights, you could do those" (300-301); Jarod, in the same interview, says "You've seen those things where you go like that, with the little springs, where you put your feet in...I can do twelve, and I like swimming, and push-ups". When asked how he knows of this, he says "I tried it...third grade, and I watched TV" (303-316). Roberta "Lifts weights sometimes, do pushups" (BT1.6, 307-308); swimming and pulling up on a bat put across two chairs were other suggestions.

\section{Curl-ups}

Students didn't have that many other suggestions besides doing curl-ups 
themselves for improving on the curl-ups test. Harriet told me "I'd rather have tummysizer than do situps."

$\mathrm{CH}$ : What's Tummysizer?

H: Tummysizer's the thing that you put around your chest, or I should say your abdominal muscle, and you push your stomach out, and you stay like that for a minute, then you come in, then you push it back out...and that strengthens your abdominal muscles...and you can even relax while you do it. (AW3.2, 102-116)

\section{Shuttle-run}

Due to the limited interview time with students, discussions regarding how one could improve their performance on the shuttle-run was very limited. When asked, students seemed very puzzled on what they could do to improve on it. Cullen (BR4.5) asks "Is there a way? Has to be a way?" (259). Jarod was one of few students when he says "Basketball...that's one good thing for the shuttle run" (BR1, 181-182).

In looking at the responses of students regarding how they could improve their scores from one test to the next, it seems that, with the exception of the milerun and pull-ups, most students felt the best way to improve on a test item was to practice the test itself at home.

Certainly, what students understand about the tests is important when looking at the overall picture they have constructed about the tests. This understanding, 
however, only represents one group of hues on the canvas of their minds. To more fully understand the total picture, we need to look at another group of hues and the contribution they make to the picture -- that of the students' teachers and peers.

\section{Category: Teacher Behaviors}

\section{Assertion Three: The urging or encouraging teacher behaviors exhibited by} teachers during the test-taking process make an impact upon students.

During data analysis, an unexpected but revealing theme began to emerge and reoccur throughout the interviews. This related to the behaviors which the teachers of students at schools $\mathrm{A}$ and $\mathrm{B}$ exhibited during the fitness testing procedures.

When the analysis of data was complete, it became apparent that students saw quite a difference between the urging, and discouraging, behaviors exhibited by the teachers who administered the tests. This is an important point to consider. When teaching, one does not present information to students in a vacuum. The interactions which take place between students and teachers constantly evolve and influence what each says, does, and feels in the context of the gym. Therefore, what students think and feel as a result of their interactions with their teachers, especially as they relate to fitness testing, becomes important to look into.

Urging behaviors are defined in this section as those which some of the students in this study have perceived to be more negative and demanding during the test taking process. Encouraging behaviors are defined as those which are supportive and positive. To best illustrate these categories of behaviors through the students' 
eyes, data have been presented below according to the headings of "urging" and "encouraging" teacher behaviors.

\section{Urging Teacher Behaviors}

Students in this study expressed, at times, very strong emotions regarding the urging behaviors exhibited by their physical education teacher. According to these students, urging teacher behaviors are characterized by teachers yelling, being strict, bossing, and getting upset if students don't perform their hardest. At times, these were related to how teachers acted during the test taking process in general. This is described by Denver:

Well, they get mad at you if you sorta' don't try your hardest, if you give up; some of the girls they sorta' get upset....if you do bad, if you don't try and just sit there and throw the blocks or something, or like when you're running, you just drop the blocks, and start laughing and start to slow down, and just play around, they get mad. (BF2.11, 19-21; 567-575)

Robert (AF2.6), agrees: "Yeah, and if you don't do it to their satisfaction, they get mad at us" (326-327). Hillary (AF3.5), in a different interview, agrees with Denver above: "...And [teacher] says 'C'mon, Hillary, you know you can do it', and it's like, I know I can but you don't have to yell at me, you know" (250-254).

Interestingly, the mile-run was the test which was mentioned most often in conjunction with the urging behaviors of teachers. Sally and Laura, for example, relate their feelings about their teachers' behaviors during the mile-run test: 
$\mathrm{CH}$ : If you walk and talk with your friends, what do your coaches do (during the mile-run test)?

L: They say get your butt moving...they start yelling at you and say, you know better than that, now just get moving.

$\mathrm{CH}$ : How does that make you feel when they do that?

S: It makes me mad.

L: That they should get out there and start running and see how they feel.

$\mathrm{CH}$ : Why does it make you mad, Sarah?

L: Cause they don't have to do it.

S: Well, that's one reason, we have to do it, and it just gives me a cramp.

L: I think they should run it with us, and see how they do.

S: See how good they are. (AR1.6, lines 304-322)

When probed further about how the teachers acted when giving the tests, Laura and Sally reflect:

$\mathrm{CH}:$...Do they act the same when they give the tests?

L: Uh-huh (knowingly). Miss [teacher] is...

S: ...mean when it comes out.

L: When tests comes she's like really strict with it.

$\mathrm{CH}$ : Really? Why do you think she's like that?

L: Cause if you're not, if you're just, when you're waiting your turn to do something, and you stop to tie your shoe, or to take off your shoe, then she'll 
yell at you, she'd say, start stretching out, and then she said take off your shoes, and then you start taking off your shoes, and she says, what are you doing, you're supposed to be stretching out! (AR1.10, 529-550)

Cindy and Nina relate their feelings about her teachers' behaviors during the milerun testing process:

$\mathrm{CH}$ : Say the coaches say, tomorrow you're going to do the physical fitness tests. What's the first thing you think of?

C: Mile-run

$\mathrm{CH}$ : You think, oh, I have to take the mile run?

C: Yeah, because they make you run...if you're running...and if you have to catch your breath and you're walking for a little bit, and they'll yell at you, and say you've got to run, this is a mile run, you don't walk this.

$\mathrm{CH}$ : Do both of the coaches say that?

N: Yes. (AW2.2, 97-110)

A few students mentioned discussing the urging behaviors of their teachers with a parent; Hillary says "When I told my mom how (teacher) acts, she said it sounds like she doesn't even want to teach us, cause she yells so much..." (AF3.4, 211-214). Sally tells what her mother remarked:

My mom tells, if she is not strict now, you'll grow up and do things wrong, if she's not strict when I'm younger, it's going to be pitiful when I'm older, but I can take that. 
$\mathrm{CH}$ : If who's not strict? Your mom, or your coach?

S: My mom, and my coach.

$\mathrm{CH}$ : Oh, both of them...so, your mom kinda thinks that the teachers should be strict on you now?

S: Yeah, so we'll do better when we're older.

$\mathrm{CH}$ : Do you agree with that?

S: So and so. (AF1.11, 551-565)

Clearly, the urging behaviors which teachers exhibited during the test taking process impacted upon the students and left at least some of them with more negative images of what test taking, and even physical education, was like. On the other hand, students described other teacher behaviors as encouraging -- and spoke of them in a much different light.

Encouraging Teacher Behaviors

Encouraging behaviors are characterized in this study by teachers giving students specific information for improving their test performances, motivating them to keep trying, and being supportive of their efforts. For example, in response to being asked if the teachers think it's important that students do well on these tests, Mary and Roberta (BT1.8) say: "Yeah".

$\mathrm{CH}$ : How do you know that?

M: Like, they're always trying to encourage you, telling you that you can do it, and they wouldn't do that if they didn't mean it. 
Roberta: They care if you do bad. (380-389)

In response to the same question, Lisa (BW4.6) says "They help you a lot, and they try to get, they try to just help you".

$\mathrm{CH}$ : What are some ways they help you?

L: Well, I'm not very good in stretching that far, they told me every night to stretch for a couple minutes, and I did better when I took the test again.

Trina tells how her teachers encourage her:

$\mathrm{T}$ : And the coaches, if you're close to beating somebody that's always been there (to the meets), they encourage you...

$\mathrm{CH}$ : Did they tell you what you could do to get better on it?

T: They tell me to keep running the track over at Jersey Gable (community track), they told me you're getting faster, Trina, you look better, just keep going, just keep exercising... (BF4.9, 457-472)

Jeremy and Sandy talk about the encouraging behaviors of one of their teachers:

J: He says, you can beat this goal, set it a little higher. He bets us on it, I bet you can do this...

C: Do you like that?

$\mathrm{J}$ : Yeah, (Coach) is the best!

$\mathrm{CH}$ : He is? That's neat! Why else do you think he's the best?

$\mathrm{J}$ : He encourages us, always... 
S: He's like my dad. (AT1.8)

Mary (BT1.5) says that the teachers talk like "They kinda encourage you to do the (best), you know, they really say, you can do it, and that kind of stuff" (254-258). Mrs. Donner, a classroom teacher, talks about the encouraging behaviors of the teachers at her school,

Oh, yes, they encourage her (her daughter) all the time, and part of the reason that she does things is because they're always telling her you can do this much more, and if you practice this, and if you do that, and you're doing good, and keep it up, and maybe you'll make the meet.

(BTHRDON.3, 141-148)

\section{Summary: Teacher Behaviors}

In listening to the students in the study, and to the tone which they used when talking about the behaviors of their teachers during the test taking process, it was clear to see that these behaviors made quite an impression upon some of the students. For some, these impressions were not as positive as it was for others. In looking at the whole picture of what students think, feel, and know about the tests, it is apparent that the ways in which their teachers interacted with them helped to color their picture - not only of the tests, but also their picture of physical education.

Besides the impact which teachers have on students, peers also helped to color their fellow students' canvases with different hues, and therefore impact on the total picture of the tests. Some ways in which this happened for students in this 
study are detailed below.

\section{Category: Students' Feelings}

Assertion Four: Many students who perform poorly on the test items receive negative feedback from peers in the form of ridicule and public embarrassment.

While the interaction between students and teachers was found to be a commonly mentioned theme through the analysis of the interviews, so were the interactions which occurred between the students themselves. The idea that children tease other children about their performances on the tests is one that many students in this study - no matter what their level of performance - were aware of; the fact that many of these students brought this subject up without any specific questions directed towards it showed it's importance in their minds.

What is paramount in Assertion Four is the fact that many students who perform poorly on one or more of the tests often feel embarrassment and ridicule from their peers who perform more successfully. Reactions from their peers usually happen during and immediately after a test performance, and happen in a variety of ways, such as students laughing, teasing, and making fun of others. Some of these interactions are discussed more fully below.

\section{$\underline{\text { Ridicule from Peers }}$}

"You know, everybody at this school knows that kids tease kids...that's just known all over, because, what do kids do?" (Ellen, BR2.7). And so begins a common data theme which began to appear as students talked about the tests and 
their peers. For example, Katherine (AF1) says students in her class tease others by saying things like

C'mon, slow poke'...Yeah, the people that are done first, stand at the finish line, they go around with them, and they act like they're helping them, but when they're not, they're just jabbing them and saying, how come you go slow, man, I can be done with this mile three times now. (471-482)

Mary says how "Well, John is really slow, and last time we did the mile run, he was the last one, and he had a really bad grade and everybody started teasing him" (BT1.11, 586-590). Robert (AF2.6) says "...If you get a bad score, I hear people making fun of people if they get a bad score" (285-288). Cailey (BT4.7) relates how "If you're slow, other kids that are really fast laugh at you a lot" (343-345). Billy (BR4.9) says "[those who do poorly on the tests] They're slower...most people call them sluggish. A lot of people pick at them because they can't run fast" (462-465). Mrs. Tele, a classroom teacher, also supports this when she says ...I've heard all those nasty remarks to each other about you didn't do so well, or you couldn't do that, or I can see sometimes they'll laugh at the children when they see them doing it...that's a problem, the fit are with children who aren't good at motor skills. (BTCHRTEL.3, 131-146)

\section{Embarrassment During Testing}

That a child may be possibly teased, ridiculed, and embarrassed by one's peers is something which causes stress to many students before and during the test- 
taking process. This is characterized by Carrie (BR2.6), who says "...One thing I don't like (when taking the tests) is when everybody is around you and you don't do so well; everybody sees you and they comment to you about it. So I really don't like that...I always get nervous. Cause I don't like people making fun of me" (299-305). Mary says "I feel kinda bad because some people hear your score, and then they tease you about it" (BT1.11, 598-600). Mrs. Beach, another classroom teacher, says I have heard some of my kids who aren't so good at p.e. talk to me about how they don't like it because they have to do it, you know, they have to do pullups, and they couldn't even do one, like I have a little girl that's heavy set in my class, and she doesn't like it when these kinds of things come up... (BTHCRBEA.1, 59-67)

As in Ellen's observation which introduced this section, it seems that most students know that teasing, embarrassment, and ridicule happen during the test-taking process. In fact, many expect it. According to Maria, "...Some of them (who perform poorly) know they're going to get a bad grade, a bad score, and some of them know they're just a little bit overweight, and way overweight, and kids make fun of them when they run" (AT4.9, 454-459). Laura (AR1.5) says this makes many of these students dislike the test because, "Some of them (those who do poorly) are kinda overweight, and they can't run that fast, and they always come in last" (248-251); Denver (BF2.9) supports this by saying "They probably just don't care...they don't really care because they know a lot of people are better than them" (482-484). 
Not all students who perform well on the tests think that ridiculing those who perform poorly should happen. Many realize that this hurts the feelings of students who perform poorly. For example, I asked Mary (BT1.11)

$\mathrm{CH}$ : How do you think that made him feel (as a result of finishing last in the mile-run)?

M: Pretty bad, because he was trying to go, and he was really tired. $(591-594)$

Karen (AF2.6) says "It's not right to make fun of some people's scores".

$\mathrm{CH}$ : But some people still do it?

K: Um-hum.

$\mathrm{CH}$ : How do you think it makes those other kids feel?

K: Bad. (291-306)

Cailey (BT4.7) thinks they feel "Sad" (352); Wanda (BW3.7) says

I think they (those who do well) should at least ask them (those who do poorly) how they did, and if it was low or high, they should tell them it was good for trying, at least, if it was low, because, sometimes my friends pat me on the back and say, well, look, I got a lower score, don't feel so bad...sometimes some of my friends are nice to me and sometimes they're bad to me. $(361-370)$ 
Ellen says how she "I try not to tease people like that...I don't tease them if they don't get something or something".

C: Well, some kids do?

E: Then it makes you really hurt inside. (BR2.7, 372-378)

Katherine and Darla (AF1.9) gives their thoughts on the matter:

$\mathrm{K}$ : (getting called names) it makes them feel bad.

D: That's another reason I think they give up.

$\mathrm{K}$ : Yeah, because people call them names, and they just get so hard inside, they just give up...everybody gets called names, but some people get called names so bad that they just try to hurt themselves.

$\mathrm{CH}$ : Who says all this stuff?

Both: Other kids.

K: Even people at stores, they stare at you and stuff. (450-470)

Interestingly enough, some students feel that the way the teachers deal with giving the tests and recording the scores contributes to the ridiculing and embarrassment felt by those who perform poorly. For example, Robert says "They know the people that are good in running, but still they ask the poor kids to do better, and if you make a bad grade sometimes they'll make you come up..."

Karen: and do it over again.

$R$ : yeah, in front of everybody, and everybody makes fun of you.

$(\mathrm{AF} 2.7,352-360)$ 
Hallie (BT2.9) says, "When the coaches ask for your score after the mile-run or something, you have to tell them, and some of the kids make fun of you and sometimes they say you're good, and you're fair, sometimes..." (452-457). Some students also feel that the way which feedback on test performances is given to students can result in embarrassment for those students who perform poorly on the tests. This is explored more fully in the following discussion.

\section{Assertion Five: The ritual of receiving and comparing scores holds different meaning for those who perform well, and poorly, on the tests.}

Any time there is a group of youngsters together, it seems that there is bound to be some sort of comparison, whether it be about one's shoes, one's toys, one's score on the math test -- or one's scores on the physical fitness tests.

In talking with students about the tests, the topic of test scores eventually came around to discussing whether one enjoyed getting their scores back, or not. From many of their answers, it seems that the receiving of feedback about performances on the test items is one to either fear or be excited about - depending upon how well you did. From talking with students, it became apparent that most students who did well on the tests looked forward to receiving their scores, telling others what they are, and comparing them against others. Meanwhile, students who didn't do well on the tests would have preferred, understandably, rather not get them back at all. Below, these two different responses are explored in further depth. 


\section{Positive Feedback from Scores}

"Do you like getting your scores back?" To students at School A, who performed well and received computer handouts of their scores during class, the answer was yes. To students at School B who performed well and received their scores in their report card, the answer was also a resounding yes. Most of these students enjoyed seeing what they did for a variety of reasons. For some, the reasons were personal -- they enjoyed knowing they did better and improved upon their scores. For example, Karen (AF2.5) says, in response to the question of whether or not she liked getting her scores back, "Yeah, so we can see what we did...what goal we met (223-225)...to find out what you did and how far you went" (246-247). Bella (BF4.10) says "You can compare scores with your last year's scores, and see if you got any better" (519-520); Billy likes receiving them so "I can see how good I did" (BR4.4, 202). Lisa likes getting her scores because "It tells you how good I'm getting (at) them" (the tests) (BW4.4, 213-214); while to Karen (BW3.13), it means "Well, I think they're fun, they're fun to do, and I can't wait till my scores come up cause I want to see what I've got...most of them I think I got in the 70's" (661-665). Jarod feels that good scores tell you "You know that you did it!" (BR1.7, 376). For David (AR3.5), getting good scores "Made me real happy, cause I knew I wasn't going to grow up being really fat and stuff, because I take care of my body and stuff like that" (263-267).

For other students who performed well on the tests, they enjoyed getting their 
scores back for a more social reason -- namely that of comparing them against others' scores. As an example, Cullen (BR4.4) thinks getting score back is good because "Sometimes it'll tell you how you did compared to the highest scores, compared to other people" (214-216). Karen (BW3.6), when asked if she felt pretty good when she got her scores back, said "Most people like your scores, and they tell each other their total scores" (310-312). Mitch says it a little more bluntly "Well (I like to get them because) I like to show people in my class" (BR1.7, 371-372). Being able to share scores with others is also important to Karen (BW3.5), who says "I like competing against other people, like in the shuttle run, we ask each other's scores, and we compare them and see who's better....(it's like) being a champion or something" (222-229).

\section{Dislike of Receiving Scores}

Not all students appreciate this practice of receiving and comparing scores, however. While some students don't mind getting good scores, they don't like getting poor ones: Mary (BT1.5) likes getting them "Except for the mile. Mine goes whoop!" (269-270), while Randy (BF3.5) says, if he didn't do well, he "Doesn't really care that much" (246). Robert (AF2.5) doesn't think they should receive any of their scores back "Because I already know how I did...because it's the same every time...when we do the tests, they tell us how good we did, and that's just going to come from the sheet, and we already know what's going to happen" (233-241). Mary (BT1.10) feels it would be "Better" if they never got their scores back (554), 
while Hillary and Chrissy relate their feelings:

$\mathrm{CH}$ : Let me ask you, what do you think about...getting your scores back? Both: Oh, no

$\mathrm{CH}$ : You don't like getting them back, Ivy?

C: I don't

H: Well, you get them, and you see, you didn't do too good,

C: You look at your paper when you get it back, and you see like she was saying, you didn't do so good, you just want to crumble it up and throw it away.

$\mathrm{CH}$ : How does that make you feel like when you get them back and you didn't do too good?

Both: Mad. (AF3, 223-243)

Getting poor scores caused some students to "Throw it [scores] away when they get on the bus, or they knew how to do the mom or dad's handwriting, and they just put their moms or dads handwriting, and so they just bring it back and say their parents looked at it" (Cathy, AT4.6, 281-288).

For some students, receiving scores back is not enjoyable because it involves listening to others act towards those who didn't do well in a non-positive way. For example, Robert says "[getting scores back] Is painful because if you get a bad score...I hear people making fun of people if they get a bad score" (AF2.6, 285-288). Wanda (BW3.7) says, about some of those whom perform well: 
People who think they're really good at it...they show off, I can tell that they like it, because they always like to get their scores, and if it's really high, they go to a person who's really low, and they say, I got better than you did, and they start showing off

$\mathrm{CH}$ : Why do you think they do that for?

W: I don't know, they just think that they're some genius. (345-357)

Norbert (AR2.8) doesn't think his scores are very good; when asked if this bothers him, he says "Yeah, sometimes..."

$\mathrm{CH}$ : Yeah, when?

N: Uhh...when everybody

Rupert: When everybody starts bragging about theirs...

$\mathrm{N}$ : When somebody, like Dan did it to me, he goes hah, hah I got something on this mile-run

R: Yeah, he's a bragger.

$\mathrm{CH}$ : Oh he is, huh? So how does that make you feel when they do that? $\mathrm{N}$ : Not too good.

R: Terrible, terrible. (404-422).

Sally (AR1.7), who did well overall on the tests, thinks teachers could do a few things differently, when giving scores back. The (teachers) "Could tell you at the end of the year and let it be a surprise, except for the poorer people, who do poor...how they're doing, separately from other people". 


\section{$\mathrm{C}:$ Oh, why is that?}

S: Cause it embarrasses them, like if the coach would have called them out in front of everybody, they would be embarrassed...I would like to find out, but different, away from other people. (344-366)

Cindy (AW2.2) says, "I wouldn't go up to them and say, ok, what's your sit-up score, ok, how many did you do, how far did you reach, how many pullups did you do...I wouldn't go up to them and ask them, I would just let them keep it to themselves, and (if) they wanted to tell me" (66-72). On the other hand, though, Karen (W3.5) says "The p.e. coaches usually tell you, they'll say at the end, you have to reveal your score to the coach, but you don't have to say it out loud" (271275).

\section{Summary: Students' Feelings}

For some students in this study, taking the physical fitness tests are an uplifting, positive experience which helps to color their picture of the tests in a positive, bright way. Unfortunately for many other students in this study, especially those who performed poorly on the tests, taking the physical fitness tests was not such a pleasurable experience.

Many times, the embarrassment or ridicule students who performed poorly on the tests may have received from their peers helped to paint their picture of the fitness tests in more negative colors. It is possible that for many of these students, the feedback which they received from these peers, when combined with their 
teachers, may have left them with a very dismal overall picture of the tests.

As we will see, a students' peers and teachers are just two of the influences which can have an impact upon their testing experiences and knowledge. The interactions which a student's parents may take with their child may have an equally important role in shaping their child's vision and knowledge of the fitness tests. This idea is explored more fully in the assertion which follows.

\section{Category: Parental Involvement}

\section{Assertion Six: Children who tend to score well on the tests tend to talk more, and differently, about their parent's interest and involvement in their fitness scores and activity habits than those who tend to score poorly}

While many students who perform poorly on the tests receive feedback from their peers, quite different than those who perform well, it is also interesting to look into the feedback and involvement which both these groups of students receive from their parents.

In talking with students in this study regarding their parents -- if their parents ever saw their scores, and if they thought that it was important for their child to do well on the tests -- it became noticeable that many of those students who tended to score well on the tests generally tended to talk differently about their parent's involvement in their test scores and activity habits than those students who scored poorly on the tests. Students who tended to score well seemed to be able to elaborate more in breadth and depth about what their parents did to tell them, help them, and 
make them do in regards to their fitness habits and scores than did the other students in this study. This can be summarized by Denver's suggestion for parents, "People, that maybe, if they have kids, they'll tell their kids, maybe help them, maybe make them fit, or something" (BF2, 550-553).

Below, how parents of students who tended to score well, and poorly, show their importance they place on their child's fitness scores and habits are detailed according to these three categories: "telling", "making", and "helping" the child to do better and become more fit.

\section{"Telling" behaviors}

Three of the "telling" behaviors of parents in this study center around those of encouragement, advice, and "just telling". The first two were more characteristic of parents of students who tended to score highly, while the last was given more by parents of those who tended to score poorly.

\section{Encouragement}

Encouraging behaviors were shown by some parents of students who were scored well on the tests; for example, when talking about his mother, David (AR3.6) says, "...Sometimes, like if I don't beat one of my scores, she'll say, she'll get me

really high up on my hopes and make me try to get up there where I can beat them [my scores]" (287-292). Trina (BF4.11) says how her dad "Wants me to be the best I can do...and he'd want me to try as much as (I) could" (562-567), and Debbie 
(AW3.7) relates how her parents are "Always saying try your hardest and get higher goals" (363-364). Just how important parental encouragement can be is summarized by David (AR3.6) when he says "I'm glad my mom cares, cause if my mom didn't care, I probably wouldn't try as much" (314-316).

\section{$\underline{\text { Advice }}$}

Advice is another telling behavior; in this study, only students who scored well mentioned that they received this from their parents. For example, Brandon (AR3.6) says how his dad "Was in the Marine Corps before, so he tries to teach my brother and I stuff that he learned, and how to do it" (303-307). Trace (BF2.7) says how his father "Sorta like trains me for the races and stuff, he likes to teach me about how to do it."

$\mathrm{CH}$ : Do you ever think about your dad and stuff when you're taking the test?

T: Yeah, sometimes

CH: Like when?

T: Like, when I run and somebody's ahead of me, I think of what he told me of how to get ahead of them. (373-385)

"Just Telling"

Students who scored poorly on the tests were more apt to be "Just told, and that's all" to do something in order to improve their scores. While their parents seem to show an interest in what their child is doing, they were usually (but not always) characterized by being brief and not followed up by further advice. For example, 
Nina (AW2.1) says, in response to what her parents would say regarding two scores on the tests which were poor "They say just try harder on the other two things, that's all" (29-30). Roberta, when asked the question, "For your scores that you said you might not do too well on, do your parents make sure you do things to help you with that?", she says, "They go, well, you did pretty good" (BT1.8, 407-412). When asked what her mother thought about her scores when she saw them, Bella (BR4.8) says her mom told her to "Practice on the mile and that's all she said" (422-423). Jeremy (AT1.9) relates how his "[teacher] Encourages us to have our parents support us".

$\mathrm{CH}$ : How do you mean? How do you know that?

J: She'll (mother) say, need to do your sit-ups.

Alicia (BF3.6) talks about how her parents see her scores:

$\mathrm{CH}$ : What do they think about them?

A: Get better.

$\mathrm{CH}$ : Really?

A: Sometimes it's rather good, and other times they tell me to do better.

$\mathrm{CH}$ : Do they tell you stuff like that?

A: Yes..

$\mathrm{CH}$ : What do they tell you?

A: Um, do curlups, exercise more, you'll pick up it when we do the mile run, my mom tells me I have to pick up my speed, make sure I run again in the 
sixth grade...A lot of things they tell me I don't remember. (316-338) "Making" Behaviors

"Making" behaviors relate to when, and the different ways, parents "make" their children exercise or be active. This was usually done in two different ways: either by having them exercise along with them, or by making sure the child was active by him- or herself. In most of these cases, it was the parent of a child who scored well on the tests that made them exercise or be active.

\section{Exercising with the Parent(s)}

Some students related ways in which they exercised with their parent(s) and/or siblings, and how this was often part of a routine. In most, but not all cases, this involved students who scored well on the tests. For example, Cathy (AT4.6) relates how "Me and my mom and my dad and my sister, we go out and run every weekend, and try to do it twice a week...me and my mom and my dad we run a mile" (312-318). David (AR3.6) says how "Me and my dad, we stretch out, then we go and run" (317-318). Sally, when asked if her mom thinks it's important for her to do well on the tests, says "Yes...my mom she makes me do exercise every day with her, we like go jogging for like five miles or something and my mom says, better keep it up...I don't like my mom's idea of fitness!" (AR1.8, 435-440). Denver (BF2.8) relates how "Sometimes, on the weekends, when I go to his (his father's) house, we run...he has all these trails in the woods, and we go on them sometimes, and we run around my neighborhood" (400-407). 
Only a few students who were scored poorly on the tests, or even "average", mentioned that their parent(s) "made" them exercise. Some of those who did include Sandy (AT1.9) who says "My mom makes me work on it (her scores); she's on a diet and all that, and she makes me work out with her. Sometimes I eat too much, but my mom makes me go around my acres...we have 3 and 5 acres". Joshua (BW2.8) tells how "My dad is pretty fit, and so is my mom, she walks a lot and everything, so now I have to walk with my mom whenever she walks, and she goes out to Jersey Gable (a local "heart trail") and walks".

$\mathrm{CH}$ : Do you like doing that?

J: Yeah, it's fun, because when I go to Jersey Gable it's fun.

$\mathrm{CH}$ : You like walking with your mom and stuff?

J: Yeah...when I go with my mom, we can talk about stuff and everything...

it's just fun to have somebody to talk to. $(415-430)$

Hillary (AF3.6) says "Sometimes I like go on bike rides with my friends, or parents, or my mom takes me up to the bus stop and she's walking" (290-295).

\section{Exercising By Self}

Some students mentioned that their parents made it a point to make sure that they exercised or worked to improve their test scores. Again, this usually was done by parents of children who scored well on the tests. For example, Jarod (BR1.9) tells how "My dad (sees my scores), because he wants to be a good athlete".

$\mathrm{CH}$ : So what kinds of things does he say to you about them? 
$\mathrm{J}$ : Well, he looks at it and if I, if there's something I didn't do very good, he'll make me practice. (469-476)

Brandon's father, who was in the Marine Corps, "Takes me in the bedroom, and he makes me do a couple situps and stuff, everyday just a few more" if he didn't do well on a test item (AR3.6, 300-307). Mia (BT2.8), who scored poorly on the tests, says how "My mom sometimes makes me and my little brother in first grade do exercises" (397-399).

"Helping Them do Better"

Some of the students mentioned different ways that their parents helped them to improve their test scores and/or fitness scores. "Helping" behaviors are defined here as those in which a parent physically helps them to work on their fitness, or provides them with help in the form of specific resources to help them improve their fitness. In most of the cases, this was discussed by students who scored well on the tests.

One example of how parents may help their child improve on the tests through providing resources, Bella (BF1.7) says how "Well, I got 55 on the pullups because I didn't do anything, and my mom, she bought me a kind of pullup thing that goes on top of your door, and every night I get the chair and I hang on it, and my mom pulls the chair, and I do some pullups" (352-359).

Another example of how parents may help their child is described by Cailey (BT4.9), who says, "They would ask me how I did, and they try to help me". 
$\mathrm{CH}$ : How do they help you do that?

C: Like when I stretch, they hold my knees [down]. (456-462)

"Helping" behaviors can also be thought of as those which show support for a child doing well on the tests and being active. While some parents of the students who scored well "helped" their children by showing an interest in their scores, some parents of students who scored poorly, or average, on the tests did not -- whether intentionally or not. For example, when Laura is asked whether her parents think it is important for her to do well on the tests, she says "No, because whenever I am running around the house, and they say settle down, and I can't, cause I have a lot of energy and I just can't get it out. Cause it's always just...it's like batteries" (AR1.9, 455-461). And Hallie says she used to go swimming at her grandmother's, "But I can't anymore, because my mother is so busy we have to go places" (BT2.2, 80-81).

\section{$\underline{\text { Summary: Parental Involvement }}$}

From talking with students about their parents and the responses of their parents to their test scores, it was apparent that students talked differently about their parents' involvement with their fitness and physical activity habits. It seemed that the students who tended to perform highly on the tests were able to talk more, and in more detail, about their parents' involvement with their testing and activity habits than those students who tended to not score as well on the tests.

Given that parents are one of the major influences in their child's life, it 
seems important to understand the different "helping", "telling", and "making" ways in which they can influence their child's fitness and activity habits. By doing this, we may begin to more fully understand the contributions which they make to their child's picture of fitness testing.

So far, we have explored the ways in which a student's understanding of the tests, their teachers, peers, and parents may color the overall picture which students paint in their minds about the tests. Yet, as with any picture, there must be a focal point upon which the eye is drawn to, and emphasis placed. For many students in this study, it seems as if the mile-run test is the center of attention in their picture. This idea is more fully described in assertions six, seven, and eight below.

\section{Category: Mile-run Test}

Part of what is so interesting about interviewing children is that they will tell you what they think -- with no need to hide the truth. Their many responses -whether it was about their performance, their teachers, or parents -- gave an indication of what they liked, didn't like, were afraid of, and what they would change about the tests if they were the boss.

During the interviews, the test item which elicited the strongest feelings was, as might be expected, the mile-run. For many students, it was the "most dreaded" test that they take in physical education; many disliked it so much that they would try to get out of taking it completely (i.e. "dodge" it) or would completely change if they were the teacher. Below, the thoughts and feelings about the mile-run are 
grouped around the two thoughts of "dodging" and "changing".

Assertion Seven: Many students dislike taking the mile-run test, some so much that they become "test dodgers".

That some students go to lengths to "dodge" the tests can be illustrated through the telling of the following two anecdotes.

$$
\text { "Jeralyn" }
$$

Mia: This girl in our class Jeralyn...

Hallie: Gosh, she's big.

M: She didn't run the mile one time, and she had to do it today because she lied, and she even told me that she was lying about not...cause she didn't want to do it, because we usually go to p.e. at 9:30, and we went to p.e. at 9:30, and we didn't do that, we didn't do the mile-run at 9:30, and so we did it at $2 o^{\prime}$ clock, and she didn't want to do it.

H: She was perfect all day long...she said her throat was hurting, and she would run around excited all day long, until p.e., then she didn't want to do it.

CH: Why didn't she want to do it?

M: Cause she didn't want to run, I guess.

H: She's not too good at school. (BT2.6, 287-305)

"Dana" (as told by peers) 
Nina: There was this girl, [teacher] told everybody, that they were going to be running the mile and everything, and she skipped school every day that they were going to do it, and the last day, she was in school, and she didn't know it, that he was going to make her run it, cause she had skipped the practice days and everything, and he took her out and made her run it, by herself, and he said that you should run it with somebody else so that it gives you a challenge...so you'll run faster.

$\mathrm{CH}$ : So did she run with someone else?

$\mathrm{N}$ : No, she had to run by herself and there were classes going by when she had to run it. (AW2.5, 241-260)

\section{"Dana" (as told by teacher)}

...And this one girl would fake injuries and stuff, and I would tell her, Dana, you're going to run the mile, you can pay me now or pay me later, and I hope you can still do it now while it's still fairly cool, but you will do it, nobody rips off [teacher]. And, (I hate to admit this), she did it the last day of school, it was about 98 degrees...it was my error, I had forgotten about it, and I happened to be looking through my fitness sheets, and said oh, my gosh, she never ran it, I can't look like a chump, so I went and got her, and she had to run it, and it was like 98 degrees outside.

(ATCHRAND.8, 398-420).

The stories of Jeralyn and Dana are just two examples of the lengths some students 
will go to miss taking the mile-run test. These "test dodgers" use a variety of methods in order to miss the tests; faking illness is one of those employed, as explained by Cathy and Maria (AT4.4):

C: And they'll sit there and fake out like they hurt something just so they can go to the office and quit doing that.

M: Some kids do that. (185-192)

Cindy and Nina (AW2.4) give their thoughts:

C: They (coaches) don't believe them.

N: I know...she said she hurt her finger, so she said that, and Coach gave her an ice pack and everything, and he was going to write a medical form or whatever, because she said that this boy ran into her and hurt her finger in p.e., so he was going to write a medical report, and when she had the ice pack he saw her playing and using her hands and everything, so he made her run it.

$\mathrm{CH}$ : Was she telling the truth?

N: No, she was lying. (166-178)

Students aren't the only ones who know that "test dodging" goes on; both physical education and classroom teachers in this study related stories of "test dodgers". Take the following example of Barbara (physical education teacher):

I mean, you have a lot of kids who don't feel they want to do it, and they have a note in their desk signed by momma that says my child cannot run the 
mile, and when we say it's mile run time, they say, time out, gotta' go to my desk, and they bring back the note that was written three weeks ago...and I have to accept it. (BTHCRBAR.5, 249-258)

Andrew says "I have a few...I have one kid in particular I'm thinking of that forged a note to get out of the mile, and I caught her, well, that's a 'U' right there, cause she doesn't want to do her work. She didn't try" (ATCHRAND.10, 539-545). Mrs. Tele, a classroom teacher, when asked "My study is focusing on the less-fit versus the higher-fit kids. Can you see any difference between those two when it comes time to take the tests? When they get scores?" says,

Oh, definitely. I've noticed it with my children who try to be absent... $\mathrm{CH}: \mathrm{Oh}$, really?

T: Yes, there's one that doesn't want, will use any excuse to get out of p.e., and they're the same children that do poorly on these tests...oh, I don't feel good, or Ms. Tele, I came in with a sore foot, or something to get out of it, I've seen that. (BTHCRTEL.3, 92-106)

While some students actually do miss school in order to miss the tests, some students wish they could, but don't, as told by Alicia (BF3.6):

$\mathrm{CH}$ : Say, if you had to think of any words in the world to describe these tests, what words would you pick?

A: Um, hard, some are hard, I don't like them, lots of words I can't think of...long, get mad, sometimes I don't even want to go to school, but, even if 
You don't go to school, you have to make the tests up, that's why I just go and get it over with. (284-290)

Joshua (BW2.3) says,

$\mathrm{CH}$ : When the coaches tell you, Joshua, just the other day, or Skyler, for you earlier, you all had to take the mile run, what was the first thing...

\section{J: AAAHHH}

S: I think throw up.

$\mathrm{CH}$ : Oh, they're not very fun thoughts?

S: Either that, or run away.

J: Like being absent.

$\mathrm{CH}:$ Really?

J: I don't like the mile at all. (145-157)

For many of these students who may not like to take the test, but end up doing it anyways, they may show a more passive kind of "test dodging" as opposed to faking illness or being absent, as explained by Amy and Tina (AT2):

T: Yeah, [teachers] can tell if you're dodging or not.

$\mathrm{CH}$ : What do you mean, dodging?

A: They just like...

T: They walk instead of run, and oh, well, this is ridiculous, just walk.

$\mathrm{CH}$ : Do a lot of kids act like that?

A: No, not in my class but I've seen some of them, they just, do it like, oh, 
no, not the mile, I can't do this.

T: They run together and we can talk the whole time.

$\mathrm{CH}$ : You can? You're allowed to do that?

T: Well, you're not allowed to, but...

A: It'll make your grade go down.

T: But that's what they...let's run the mile together, and talk the whole time.

A: And some of them can get a really good score but they wait up for their friend or whatever, and they end up getting a bad score. (AT2.3, 120-142) And so goes the story of Jeralyn...and Dana...and many other students to whom the mile-run test is something to be missed, at almost all possible costs. One may wonder, though, just why do so many students dislike taking this test so much? Why do they hate it so much they have to lie, play hooky, or fake illness to miss it? To some, it is a matter of pain and discomfort, as described below by Susan and Evelyn:

S: (to Evelyn) You don't like to run?

E: U-uh

$\mathrm{CH}$ : Why don't you like to do the mile?

E: Well, for one thing we have to run one mile, and finish and it makes my side hurt and my stomach. (AW4.8, 388-393)

Karen (BW3.12) gives her thoughts on the subject: "I don't like running two laps around the two baseball fields. It really hurts you" (633-634); as does Billy: "It's too 
long...every time I run it I get sick" (BR4.5, 273). Laura discusses her views: "It always makes my side hurt...every time I run the mile, it feels like a nail is going right through my side" (AR1, 33-36; 223-224). Hillary agrees when she says:

...You get sick of trying to do the mile-run and your side's hurting, and you start walking, and people say "run Hillary run", like last time she told me to run I just kept walking cause my side was hurting, and they make you run when you don't want to, unless you're in a running mood, you don't want to run. (AF3.2, 78-87)

Bella concurs with Laura and Hillary when she says: "Well, it takes a long time, and it makes you really tired, and after you've been running for a long time it starts hurting" (BF1.3, 111-114). Joshua feels that weather has something to do with it when he says "Yeah, my time was like, most of the time it gets really hot when we have to run it, outside, right out there...we have to run the lap twice, and we're always in the sun...we usually end up walking it, most of the way" (BW2.3, 115121).

For other students, disliking the test is a matter of taking too much time and effort, as explained by the following students:

Harriet: ...I don't really like the mile-run, even though it helps you beat your goal and everything, and you start getting faster, it really tires me out, I usually have to be sitting down for about an hour, not walking around, not doing anything, and then I can run the mile and I'll get a very good score. 
(AW3.5, 241-248);

Cindy: "Sometimes when I'm in a good mood, I like to run, but I don't like to run too many because then I get all tired and stuff" (AW2.3, 117-120); and Jarod: "I would take all of (the tests) except the shuttle run and the mile".

$\mathrm{CH}$ : Really? Why wouldn't you take those?

J: I don't want to.

$\mathrm{CH}$ : How come?

J: The mile's...too long. (BR1.3, 129-135)

So, while some students look forward to running the mile run with eagerness and anticipation, we see that others wish they were a world away. But what can be done about changing the mile-run so that it is not so painful or boring to students? To find this answer, students were asked to tell what they would change about the milerun if they had the chance. Their thoughts are presented in the final assertion, number eight, below.

\section{Assertion Eight: Given the chance, many students would change the mile-run to make it more fun.}

When asked what they would change about the mile run if they were given the opportunity, students had some interesting thoughts about what they would do. Most of these thoughts centered around the concept of making the test more "fun". As an example of how she would make the mile run more fun, Cailey 
(BT4.7) says she would "Make them like, I'd make something funner than just running, I'd make it having to jump over cones or something when you're running" (380-383). Sandy says she would "Invent some kind of soccer game or something cause I hate running the most" (AT1.11); Alicia (BF3) would change the mile run to "A fun game". Then, you have Mary and Roberta, who say:

...If I was the coach, I would make it into something fun, you know, like playing kickball, having to run back and forth two times or three times however much they made you run for the mile run, and you could be timing it without them knowing it, so it could still be fun.

$\mathrm{CH}$ : Oh, so you mean when you get timed that makes it not fun?

M: Yeah.

R: Yeah, cause then that makes you think about being timed, and you think it's something we have to do, so it's not really fun.

M: Yeah, it's a fact. (BT1.10, 533-549)

Roberta, in the same interview, says she would "Probably change the mile to a half mile, because the half mile's a lot easier, and it would make the kids want to try harder" (BF3.9, 474-483). Joshua says that "I think they should do for the mile is take your time for the quarter mile and quadruple it. Might be easier" (BW2.1, 3941). And though Laura's thoughts are not specific to just the mile-run, she seems to summarize the thoughts of many:

I wish they would just change...they wouldn't be there, you could just do 
what you wanted, they bring out all the equipment, and you could just play dodgeball...just make it funner, like the tests you could make it funner, like making it a game. (613-631)

\section{Summary: Mile-Run}

It became clear from talking with the students in these interviews that many (but not all) of them did not think much, or highly, of the physical fitness tests. As much as some students may have liked the tests, there seemed to be more who disliked it. Of all the themes, this seems to be the one which perhaps most clearly shows the differences between a child's way of doing or perceiving events -- and an adult's. The strength and conviction which many of these students spoke with, throughout this theme as well as the others, serve as a reminder to us adults of just what it means to be a child taking these tests two times a year, each year during their school career.

\section{Discussion of Results}

Students interviewed as part of this study showed they had an incomplete understanding of why they took one physical fitness test battery and the test items in that battery. Too, they had little understanding of how they might improve on these test items, other than replicating the same test items at home.

Based upon pilot testing of this study's methodology, these results were not wholly unanticipated. What was unexpected, however, was the number of students who didn't show a complete understanding of the purposes of the tests, or how to 
improve on them -- even after having taken the tests twice a year, for three or four years previous to this one.

One factor which may account for this incomplete understanding is the more concrete, versus abstract, level of cognitive development which is common to students of this age and developmental range (McNally, 1977). Their limited understanding of adult, abstract terms and definitions undoubtedly made a difference in how fully students at both schools understood, and could articulate, the concepts that underlie the reasons for the physical fitness tests. Even with their limited understanding of abstract terms, however, it would be hoped that more students could have more clearly communicated the purposes for the tests -- rather than having no idea at all why they were required to take the test annually.

Another interesting finding relative to the students' understanding of the test items and the corresponding component of fitness each one measured was that students at School A, who had a specific unit during which they formally learned about concepts of fitness, didn't necessarily show a more complete understanding about the tests than did students at School B, who had no such formal fitness instruction. It was also unexpected, given this, to see the number of students at School B who showed an understanding of the reasons for taking the tests. It should not be inferred, however, that one programmatic approach was better than the other. Certainly, there are many factors which could account for the differences.

One of these may be any differences in how teachers communicated the 
concepts about the tests' purposes to students. Perhaps some teachers were better able to "match" their explanations to the children's level of understanding of what can be very abstract terms (McNally, 1977). Another reason could be that students at School B seemed to feel more comfortable in the presence of an interviewer whom they did not know, and thus were able to verbalize their thoughts slightly better in an interview setting than were students at School A. Perhaps the fact that students at School B came from a suburban setting -- versus the rural setting of students at School A -- and were more likely to be exposed to a greater number of interactions with adults whom they did not know than were students at School A made a difference. While it was not anticipated that the researcher, as a "native" to the area, would have problems interacting with the students in either setting, it is possible that the researcher's presence affected students at School A to a greater degree than for those at School B.

Too, the difference between responses from students at Schools A and B may have been that the researcher's skills in interviewing students could have improved as a result of first interviewing students at School A. While a pilot study was done prior to this study, certainly, the experience of interviewing a large number of students may have contributed to qualitative differences in how the interviewer, and students, reacted to the interview setting.

A fourth possible reason may have been that students at either school could have been influenced by the short written "quiz" which was given to them before 
they were interviewed. It may be that having the chance to deduce the answers to these questions, especially if they did not already know the exact word for the component of fitness a test item measured, may have allowed some students the chance to "remember" an answer and present it during the interviewing process. This was alluded to during one interview; fortunately, however, the follow-up questions asked of students did help in some degree to "flesh out" if students really knew the answer or were just repeating a word they may have remembered. Just the same, though, it cannot be ruled out that for some students, taking the quiz first may have impacted some of their answers. Too, the words used for the questions asked on the quiz may have been more familiar to students at one school versus the other.

Lastly, the differences between students at either school may be that the teacher behaviors during test taking impacted not only how students felt about the tests, but they may have also affected students' motivation to learn about fitness concepts and thus the tests, as well. For example, the totally unexpected finding which related to the negative feelings which students at one school had regarding the tests and the teacher(s) may have made a difference in how, and how much, students learned about the fitness concepts. Conversely, perhaps the positive perceptions which some students had about the fitness tests and their teachers' behaviors during this time made them more "open" to learning about concepts of fitness.

One anticipated finding during this study was the fact that some students at both schools, usually those who scored poorly on the tests, were subjected to ridicule 
and embarrassment from their peers as a result of their poor test performances.

Given the idea that most individuals prefer to be thought of in socially positive ways, it is not surprising that some of these students would routinely try to get out of taking the tests by faking illness, injury, etc. Certainly, these students were not the first ones to ever do this, nor would it be realistic to think they would be the last!

In summary, some results from this study were anticipated while others were not. No doubt this is similar to what happens with many other studies! No matter what the findings, however, it should be noted that students in both schools appeared to be very honest. This suggests that what students said in their interviews was a true revelation of what they thought, and what they understood, about one physical fitness test battery and the items in that battery. It is from these revelations that we as adults can begin to have a greater understanding of the possible relationships between children and the physical fitness tests. 


\section{CHAPTER V}

Conclusions, Implications, and Recommendations

This study sought to discover what fourth and fifth grade students, at two different schools in the same school district in a large southeastern state, understood and felt about one physical fitness test battery and the items in that battery. As a means of accomplishing this, over 50 girls and boys were interviewed by the researcher during their physical education class time. When possible, interviews were conducted with students who tended to score well, or poorly, on the tests. In addition, interviews were conducted with the students' physical education teachers, classroom teachers, and administrators at either the school or school district level. As a result of analyzing the interview data for common themes, various findings were discovered. From these findings, certain conclusions, implications for teachers, and recommendations for future research can be drawn. Concluding statements will first be presented below; implications and recommendations related to these conclusions will follow.

\section{Conclusions}

It is clear from this study's results that the students who were interviewed have varied and at times profound knowledges and feelings about the physical fitness tests. Taken singly, these thoughts are informative and at times humorous; when looked on as a whole, the many similarities among them give us an idea of what it is like for at least some nine- and ten-year olds to take the tests twice a year. 
The common threads of these students' thoughts are summarized in the following conclusions.

The first conclusion relates to the understanding which students in this study have about the tests and how they could improve their performance on these test items. It was found that most students in this study did not have a complete understanding of why they were taking the test battery as a whole or specific test items, or even how they could improve their performance on these test items. For example, some students were able to relate a component of fitness (e.g. muscle strength, flexibility) with the test item which measured this component, yet were not always able to further fully explain and define what this component meant. Too, many students' responses as to the purposes of the test items seemed incorrect when compared with their teachers' explanations for the same purposes. A possible explanation for this lack of complete understanding may be a reflection upon their level of cognitive development. For example, given that children's level of cognitive functioning at this age tends to be more concrete, rather than abstract (McNally, 1977), it is possible that their lack of full understanding about the purposes of the tests and the related concepts of fitness is due to receiving instruction in concepts that are too advanced for their current level of cognitive development.

Second, in agreement with Fox (1988), the teachers in this study had a positive influence on children's attitudes "simply by the quality of their interactions" (p. 243) -- i.e., their encouraging behaviors. It seems that the converse was also true 
-- that the urging behaviors shown by teachers also had a negative influence on some students in the study. Results of this study show that the behaviors which teachers exhibited during the test taking process clearly made an obvious impact on at least some students in this study. Students were easily able to distinguish between and discuss the urging, and encouraging, behaviors which their teachers exhibited during the test-taking process. Urging behaviors such as yelling, being strict, bossing, and getting upset, and encouraging behaviors such as giving specific feedback on performance, motivating, and being supportive seemed to impact not only on what some students felt about the tests, but also to color the larger picture of physical education in general.

Third, the interactions which took place between peers clearly made an impression upon the picture which some children, especially those who tended to score poorly on the tests, had painted in their minds about the tests. These impressions came as a result of ridicule and public embarrassment they received from their peers in the form of teasing, being made fun of and laughed at due to their poor performance on the test items. These interactions seemed to impact more than just the feelings which these students had about the tests; they also seemed to influence feelings they held about themselves and physical education, as well as those which other students held about them.

Fourth, interactions which students had with their parents was another interesting theme which ran through the interviews in this study. Students were able 
to delineate different behaviors which their parents exhibited (i.e. "helping, "telling", and "making"). Perhaps more importantly, there seemed to be a difference in the quality of these behaviors as told by students who tended to score well, and poorly, on the tests. In general, parents of students who tended to score well seemed to give more encouragement and advice to their child; they made sure their child exercised and was active; and they seemed to help their child improve their test scores by either physically helping them or by providing resources which could help them improve, than parents of those who tended to score poorly on the tests.

And lastly, the feelings which students expressed about the test items and the mile-run in particular remind us that the tests can be a painful and humiliating experience for many students. Many of them (who tended to those who scored poorly on the tests) disliked taking the tests so much that they would "dodge", or fake illness or be absent, just so they didn't have to take the tests. Most students did understand, however, that they were required to take the tests, and so, their "dodging" came in the form of putting minimal effort into taking the tests. Again, these more negative experiences seemed to not only affect students' feelings about the tests, but many times of physical education and other activities, as well.

In summary, the results of this study show us that students hold a multifaceted picture of the physical fitness tests. The use of the interviews in this study allowed us to look more closely at these pictures and discover why they were composed in the manner they were. Clearly, the myriad of interactions which took 
place between these students and their parents, peers, and teachers all helped to contribute to these formation of these pictures.

Results from this study give us as teachers some insights into how we may critically examine our own physical fitness testing practices. In addition, they may lend some further insights to the field as we continue to look at and determine what is developmentally appropriate, and inappropriate, in the teaching and (in this case) the physical fitness testing of children. Therefore, some important implications which results of this study may hold are discussed in the following section.

\section{$\underline{\text { Implications }}$}

The many insights found in this study are representative of only what children at two different elementary schools feel and know about the physical fitness tests. It is possible, though, that at least some of these may be familiar to teachers who have experience in administering the fitness tests to students. As such, the following section will seek to present implications which the results of this study may hold for practitioners. These three areas of implications relate to: 1) developmentally and instructionally appropriate practices involving the fitness tests; 2) the involvement of parents with students' physical fitness; and 3) the "authentic" assessment of fitness.

\section{Developmentally and Instructionally Appropriate Practices}

The recent emphasis on defining and evaluating what is developmentally and instructionally appropriate for children in physical education (NASPE, 1992) holds 
much promise for improving the way teaching and curricular practices are approached by teachers. Results from this study can add to our understanding of what is appropriate for children in relation to the fitness testing of children. Those which hold possibly the largest implications for teachers and teacher educators include understanding about the concepts underlying the tests, teacher behaviors, and solo assessment. These are discussed in more detail below.

\section{Students Understanding of Test Concepts}

The first area of results pertaining to developmentally appropriate practices regards students' knowledge of the tests. Results of this study showed that most students interviewed did not show a complete understanding of why they took the physical fitness tests. As a true developmentally appropriate approach to teaching includes understanding how children think as well as how we as teachers can be responsive to this thinking, then perhaps it is germane for teachers to explore ways in which the tests', and their related concepts of fitness, could be explained in terms that more fully "match" our students' level of understanding (McNally, 1977;

NASPE, 1992). By doing this, we may help them to not only more fully grasp the reasons and concepts underlying the fitness tests, but we may also help to ensure that their understanding is meaningful and relevant to their level of physical and cognitive development.

Students' lack of understanding about the tests brings up a different, interesting question. If students aren't fully sure or have no understanding of why 
they are being tested, is it possible for these same students to perceive their performances on the tests as a subjective measure of their physical competence, rather than as an objective, evaluative measure of their health-related fitness? And if this is the case, it may lead one to ask -- should the tests even be administered to students until they are able to more completely understand why they are taking them? Given the full, abstract lack of understanding about the tests by students in this study, this may be an important question for their teachers to focus on.

\section{Teacher Behaviors}

As teachers, all of us want our students to perform well on the fitness tests. After all, their performances -- especially if good -- can be a powerful validation of our job as the students' physical education teacher (no matter whether these results were truly a result of our instruction and practices or not). Too, the fact that a school's fitness test scores are many times reported to school boards, parents, principals, and the public as a measure of accountability in physical education have helped to increase the pressure for students to perform well, and hence, for teachers to encourage students to perform well.

Results from this study, however, show that care must be taken when verbally encouraging and motivating students to perform better on the tests, especially the mile-run. Feedback such as "C'mon, you can do it!" and "Get going -I know you can run faster"! may be perceived by some students as positive and motivating, while to others, especially those who tend to perform poorly on the tests, 
they may be perceived as authoritative and punitive.

This suggests that we as teachers should strive to keep a lighthearted, humorous approach to testing as much as possible - using a "firm, but warm" (Graham, 1992, p. 36) environment. By monitoring our feedback and approaching students during test taking with empathy, encouragement, and even humor, perhaps many negative effects of what are grueling physical (and psychological!) tests for many students can be altered.

\section{$\underline{\text { Solo Assessment }}$}

The third area of implications from this study's results reflect the public arena in which students perform the different test items and in which scores are recorded. This mostly impacts upon those who tended to score poorly on the tests -the same students whose attitudes and health habits we need most to influence. In the document Developmentally Appropriate Physical Education Practices for Children, developed by experts in the area of elementary physical education for the Council on Physical Education for Children (NASPE, 1992), the practice of assessing students one by one while doing gymnastics routines (while their peers wait and watch) is seen as an inappropriate teaching practice. This leads one to wonder about the similar methods of assessment which are utilized during fitness testing, and whether it exacerbates the public arena children perform tests in. From students in this study (especially those who scored poorly), we know that trying to perform pull-ups or run the mile run while their faster and stronger peers 
watched resulted in deeply humiliating experiences for them.

For example, students in this study described their discomfiture as their classmates, waiting to perform the pull-ups test, watches while he or she tried to do a pull-up -- and failed. Other students who tended to finish near the end of the class in the mile run told of situations in which they were nearly the only one finishing the test; they would be teased and made to feel embarrassed about their slow performance in the test by those in the class who were done and watching. Given the very public nature of these performances, it is no wonder that many told instances of "dodging" the tests (i.e., faking illness or injury, being absent, or just plain not trying) as a way of avoiding what we can only interpret as psychologically and physically painful experiences for them. This leads one to wonder if other students who take the tests in similar situations may also feel the same way. Given this possibility, it becomes germane for us to also include the solo assessment of fitness tests as an inappropriate practice when administering the physical fitness tests.

One possible solution to the use of solo assessment may be the use of alternative methods of testing such as self-assessments. By not administering the tests "en-masse", or in large group settings, it is possible that teachers can still allow students to assess their levels of fitness without the added pressure of performing in front and being compared to one's peers. Students could also be given the opportunity to work in these situations with a partner. Both of these methods may 
allow for students and teachers to privately record and receive scores.

In summary, it is increasingly being found that many teachers and teacher educators are looking carefully at traditional instructional practices and content in physical education in terms of how they impact upon children's cognitive, affective, and physical development in physical education. Results from this study suggest that we as educators should take a closer look at how we administer the physical fitness tests to children and find new ways to deliver the tests, concepts about these tests, and scores in manners which preserve the dignity and respect of all students. By doing this, we can make a positive impact on the interest and physical activity participation patterns of all students -- not just those who tend to score well on the fitness tests. In addition, we come closer to "physically educating" students not only for the present, but for their future lives, as well. This reflects a growing emphasis in education on looking beyond what is taught today to how it will affect students tomorrow. Certainly, this involves not only students' experiences at school, but also at home. As such, the following section addresses the role of parents in their children's fitness and activity habits.

\section{Parental Involvement with Children's Fitness}

Increasingly over the past few years, parents have been urged to become more involved with their child's fitness and activity habits. To aid in this, a greater number of schools and physical education teachers are planning programs which 
involve the parent and child together with fitness related activities; in addition, resources are being made available to the general public which target how parents can get positively influence their child's health and fitness habits. This has happened in part because of the decline in children's fitness levels and of course, the great impact which parents have in the developing habits of their children.

In this study, students' thoughts suggest that the quality of a parents' "making, telling, and helping" behaviors can make a difference in how they influence their child's fitness behaviors. Some parents were able to give specific feedback to their children on how to improve their test performances; others were not able to do this. Some parents actively involved their child with them when exercising, or helped them to exercise, while other parents were not able to. One question left from these findings is that perhaps some parents weren't able to give their child more specific feedback or help with their fitness and activity habits because they weren't sure of what feedback to give. This may be very possible; for example, it is likely that most parents did not learn about fitness when they were in school, and even if they did, that knowledge about what is and is not correct in relation to fitness has changed greatly in the past few years. Much of the information available on fitness today seems to be confusing and misleading. Given this, it may be worthwhile for physical education teachers to make current knowledge on fitness and activity available for parents; by doing so, they may be more able to give correct, specific feedback and help to their children. 
Another implication is to give parents suggestions of active, fun ways which they can participate with their child, if they so wish. By making information available on gifts that are activity related, for example, parents may encourage their children to be more active at home.

Teachers may also want to think about offering a "check out" option, similar to a library, that would allow students to take equipment such as balls or jump ropes, home for the weekend. This way, students and parents who are in more remote areas or who may not have the opportunity to be involved in community leagues, etc. can still be involved in healthful activity.

In summary, parents have a large impact on their child's health and fitness habits. Physical education teachers can be a powerful force in providing parents with current, correct information and possible access to information and equipment which can allow them to take more greatly impact their child's activity habits, as well as to make more informed choices regarding these habits. By doing so, fitness and physical activity can become more meaningful to children's lives; this concept is addressed in the next section, which focuses on the authentic assessment of children's fitness.

\section{The Authentic Assessment of Fitness}

Leading educators in the profession today agree that it is not only important that students become physically fit at the present, but that they also understand and value fitness in order to be fit throughout their lives (Franck, et. al., 1992). It is also 
recognized that, in order for fitness knowledge and skills to be important to students for a lifetime, they must be relevant to them and the world they live in. This emphasis on the "realness" of fitness directly impacts the assessment of fitness. But what does the term authentic mean? And what difference can it make in fitness testing?

Recent research tells us that authentic assessments are those in which the student demonstrates the desired behaviors in a real-life, rather than contrived, context (Meyer, 1991). Factors which control the authenticity or "realness" of an assessment include whether control over the testing outcomes and situation rests with the student or teacher, as well as the motivation, conditions, and spontaneity involved in the assessment. Authentic assessments are on the opposite end of the "real-life" continuum from standardized, multiple choice tests, for example.

From talking with students in this study, it became clear that many of them saw the fitness tests as more traditional rather than authentic. Students who scored well and poorly on the tests distinctly realized that they "had to" do the tests on a day and at a time that was dictated to them. It didn't matter how good they felt that day, whether they were mentally prepared to take the tests, or even many times what the testing conditions were (e.g. hot weather). They had no control over what tests they could take; the only accepted way to test one's cardiorespiratory fitness, for example, was through the use of the mile-run test.

Some students (mostly those who tended to score poorly on the tests) knew 
they would never score the best, or even well, on the tests -- no matter how hard they tried. They had given up hope of ever doing as well as their peers. Martinek and Griffith (1994), in summarizing a study of third grade children, noted that one of the main reasons for children to give up quickly or avoid any engagement in a task is their sense of having little control over the outcomes of achievement situations. They state, if "success or failure, in their eyes, is beyond their personal control, [then] why bother?" (p. 108). This perceived lack of control by students has been shown to relate to the condition known as "learned helplessness" -- in which students "learn" that they are "helpless" in certain situations. While it cannot be said for sure that students in this study exhibited this condition, certainly there seems to be a chance that this might indeed be the case.

Too, many students saw little or no spontaneity (i.e. fun?) in the taking of the tests. The one exception was the shuttle-run, which many students saw as more fun and exciting. Many times the tests (especially the mile-run) was described as "boring". The fact that students, if given the choice, would change this test to make it more fun or "like a game" reminds us that children are not miniature adults. They do not have the attention span of adults, nor do they think in the same manner as adults. Theirs is a world which in which playfulness and fun are the orders of each day. The current fitness tests -- which were designed by adults -- do not seem to mesh very well with children's perceptions of the world and what they see as being important and meaningful to their lives. From a child's perspective -- and 
increasingly, many adults -- these tests are not authentic.

For many students in this study, the above factors clearly helped contribute to a lack of motivation on their part to do well on the tests or even to take them. Can we blame students, however, for their lack of interest and motivation for taking these tests? How many of us would be motivated to take the tests or do well under the same conditions? And what does all of this mean for how we as teachers structure and administer the fitness tests to students? Since it is likely that no one will be there to tell students, when they are adults, that they should test their fitness or even participate in fitness-enhancing activities, then perhaps we should begin to give students more control over their own fitness, especially testing, when they are children. Some suggestions on how this might be done follow.

First, teachers could explore ways which allow students to self-test themselves at various, frequent occasions during the year (Corbin, 1993) instead of performing all the tests within the time span of a week or more. Students could keep track of how they score on a variety of fitness indicators, not necessarily just those prescribed by a testing program. If teachers are required to turn in test scores for each year, perhaps they could give students a cut-off date for when "official" scores of "official" tests need to be given to them. This method of self-testing may not only provide students with a more developmentally appropriate and authentic testing situation, but it could feasibly be done by students while at recess, home, or during physical education time with a classroom teacher. 
Second, some examples of how the testing process itself could be made more authentic include: instead of performing a test item like the mile-run, perhaps one student may choose to time how long it takes him or her to ride a bike (perhaps to a friend's house) while another sees how long or many times he or she can jump a self-turned rope. Or two friends may decide to walk/jog and talk over a specified distance, seeing how fast they can go by timing themselves on their own or a teachers' stopwatch. Here are some students gave suggestions for making the "boring" mile-run more "fun" (i.e. authentic!): getting the chance to jump over hurdles while they ran (i.e. an obstacle course), or being timed for their running while playing a game which involved continuous running such as soccer. Too, students could have a choice of whether to use pull-ups, push-ups, "partner pull-ups" (as described by students in this study), or even how far they get across the "monkey bars" on the playground as a measure of arm and shoulder girdle strength. Certainly, there are many other activities which show a more "fun" and "real" use of specific components of health-related fitness. While using any of these situations may not be as valid as measurement specialists would prefer, one may ask, does this really matter? If the end result is to get children fit and active for a lifetime, isn't it more important for them to be involved in potentially more motivating, meaningful, and life-like activities than taking a test deemed valid and reliable on the basis of research in laboratory settings?

In summary, there is an increasing call for student assessments to be more 
authentic to their world. If we are to physically educate students for a lifetime, their involvement in participating in activities, learning fitness knowledge, and monitoring their own fitness levels must be done in a manner which is more meaningful to them. Through these positive experiences, it is hoped that students will come to value what fitness means to them and why it is necessary for their life -- and then decide to keep it a part of their life, long after their school years are over.

\section{$\underline{\text { Recommendations for Future Research }}$}

As happens at the conclusion of many studies, one is left with some interesting findings, some not so interesting, and a host of additional questions which you wish you had been able to explore! This study was no exception. By talking with students in an interview setting, a number of questions are left unanswered, but may be important enough for future research. These are discussed below.

First, given the emphasis on increasing one's knowledge relative to fitness as a key ingredient in becoming physically educated (Franck, et. al., 1992), it seems important for future research to look into just what concepts of fitness are appropriate to be taught to students in the elementary years. What can students realistically be expected to know -- and fully comprehend -- about the components of fitness and the fitness tests while they are in elementary school? How can we best communicate knowledge about abstract concepts in more concrete terms for children? By understanding this more, perhaps we as teachers will have a better idea 
of how to make fitness instruction more appropriate for elementary childrens' cognitive developmental levels. Little research has been done which explores this important question, and should be a focus for further investigation.

Second, an interesting point that some may wish to delve further into is the difference between how boys and girls felt and what they knew about the tests, and how they perceived their competence in the physical arena. During the interviews, some intriguing insights surfaced which were not a part of the study but would be interesting to find out more about. For example, even by the fifth grade, girls seemed to be very aware of their body image and being "skinny" or not. Other girls mentioned or implied that they were not supposed to do as well as the boys on the tests ("because everyone knows girls aren't as fast as boys"), yet others expressed surprise when they or their friends did better than the boys. Too, some comments suggested that girls who liked and scored well on the tests sometimes received pressure from their peers for doing so, in the form of teasing, being called a "tomboy", and having their friends upset at them.

A third area which future researchers may wish to look into are the differences between programs which take different approaches to fitness testing. For example, does the approach taken by the teacher (i.e. goal-setting vs. traditional) make a difference in students' knowledges and feelings about the test? Also, it seems important to identify programs which use self-testing as a means of testing children to see if there is a difference in how students react and think about the tests. 
Another interesting and needed approach would be to examine the effects of a testing situation -- in terms of knowledge and attitudes -- which involves students in more authentic types of testing situations versus traditional testing situations. It seems important to determine whether the traditional, adult-oriented fitness test is indeed the most appropriate way of determining children's fitness levels -- and the long-term influence on their attitudes about physical activity.

A fourth area of future research might involve looking more closely at the interactions between parents of students who tend to do well on the tests, and those who do not. Certainly, this could be a lengthy study in itself! It would be interesting to involve these parents and their children in a case-study to explore the interactions between parents and children in regards to their fitness and activity patterns, and how and what they know about fitness and the fitness tests.

In summary, as regular participation in physical fitness and activity becomes even more recognized as an important contributor to the health of Americans, a greater emphasis will continue to be placed upon children becoming more physically active. As this occurs, it will become increasingly important to understand the thoughts and feelings of children about not only fitness tests, but more importantly, the role of regular physical activity in youth -- and for a lifetime. 


\section{REFERENCES}

American Alliance for Health, Physical Education, Recreation, and Dance.

(1988). Physical Best: The American Alliance physical fitness education \& assessment program. Reston, VA: AAHPERD.

Alton-Lee, A. \& Nuthall, G. (1990). Pupil experiences and pupil learning in the elementary classroom: An illustration of a generative methodology. Teaching and Teacher Education, $\underline{6}(1), 27-45$.

Amato, P. R. \& Ochiltree, G. (1987). Interviewing children about their families: A note on data quality. Journal of Marriage and the Family, $\underline{49}$, 669-675.

Bar-Or, O. (1987). A commentary to children and fitness: A public health perspective. Research Quarterly for Exercise and Sport, 58(4), 304-307.

Blackwell, Jr., E. B. (1990). Physical fitness is a central curriculum issue. Journal of Physical Education, Recreation, and Dance, 61(1), 18.

Blair, S. N. (1992). Are American children and youth fit? The need for better data. Research Quarterly for Exercise and Sport, 63(2), 120-123.

Blair, S. N., Clark, D. G., Cureton, K. J., \& Powell, K. E. (1989). Exercise and fitness in childhood: Implications for a lifetime of health. In C. V. Gisolfi \& D. R. Lamb (Eds.), Perspectives in exercise science and sports medicine, Vol. 2. Youth, exercise, and sport (pp. 401-430). Indianapolis, IN: Benchmark Press. 
Bogdan, R. \& Biklen, S. (1982). Qualitative research for education: An introduction to theory and methods. Boston: Allyn and Bacon.

Bondy, E. (1990). Seeing it their way: What children's definitions of reading tell us about improving teacher education. Journal of Teacher Education, 41(4), 3345.

Carpenter, T. P., Fennema, E., Peterson, P. L., Chiang, C., \& Loef, M. (1989). Using knowledge of children's mathematics thinking in classroom teaching: An experimental study. American Educational Research Journal, 26(4), 499531.

Colquhoun, D. (1990). Enough aerobic activity in physical education? The answers are educational and not technical. Journal of the International Council of Health, Physical Education and Recreation, 26(4), 15-20.

Commins, N. L. \& Miramontes, O. B. (1989). Perceived and actual linguistic competence: A descriptive study of four low-achieving Hispanic bilingual students. American Educational Research Journal, 26(4), 443-472.

Corbin, C. B. (1987). Physical fitness in the K-12 curriculum: Some defensible solutions to perennial problems. Journal of Physical Education, Recreation and Dance, $\underline{58}(7), 49-54$.

Corbin, C. B. \& Pangrazi, R. (1993). Physical fitness: Questions teachers ask. Journal of Physical Education, and Recreation and Dance, 64(7), 14-19. 
Corbin, C. B. \& Fox, K. R. (1985). Fitness for a lifetime. British Journal of Physical Education, 16, 44-46.

Corbin, C. B. \& Pangrazi, R. P. (1992). Are American children and youth fit? Research Quarterly for Exercise and Sport, 63(2), 96-106.

Dempsey, J., Kimiecik, J., \& Horn, T. (1993). Parental influence on children's moderate to vigorous physical activity participation: An expectancy-value approach. Pediatric Exercise Science, $\underline{5}, 151-167$.

Denzin, N. K. (1970). The research act. Chicago: Aldine.

Dishman, R. K. \& Dunn, A. (1988). Exercise adherence in children and youth. Implications for adulthood. In R. K. Dishman (Ed.), Exercise adherence. Its impact on public health (pp. 155-200). Champaign, IL: Human Kinetics.

Erickson, F. (1986). Qualitative methods in research on teaching. In M.C. Wittrock (Ed.), Handbook of Research on Teaching (3rd ed., pp. 119-160). New York: MacMillan.

Ford, M. (1989). Students perceptions of affective issues impacting the social emotional development and school performance of gifted/talented youngsters. Roeper Review, 11(3), 131-134.

Fox, K. (1988). The self-esteem complex and youth fitness. Quest, $\underline{40}, 230-246$.

Franck, M., Graham, G., Lawson, H., Loughrey, T., Ritson, R., Sanborn, M., \& Seefeldt, V. (1990). Definitions of the physically educated person: Outcomes of quality physical education programs (Report of the Physical 
Education Outcomes Committee). Reston, VA: AAHPERD.

Freedson, P. \& Rowland, T. (1992). Youth activity versus youth fitness: Let's redirect our efforts. Research Quarterly, 63(2), 133-136.

Gilliam, T. G., Katch, V. L., Thorland, W., \& Weltman, A. (1977). Prevalence of coronary heart disease risk factors in active children, 7 to 12 years of age. Medicine and Science in Sports, 9 (1), 22-25.

Going, S. \& Williams, D. (1989). Understanding fitness standards. Journal of Physical Education, Recreation, and Dance, 60(1), 34-38.

Graham, G. M. (1992). Teaching children physical education: Becoming a master teacher. Champaign, IL: Human Kinetics.

Graham, G., Hopple, C., Manross, M., \& Sitzman, T. (1993). Novice and expert children's physical education teachers: Insights into their situational decisionmaking. Journal of Teaching Physical Education, 12(2), 197-214.

Harter, S. \& Pike, R. (1984). The pictorial scale of perceived competence and social acceptance for young children. Child Development, 55(6), 1969-1982.

Hutchinson, G. E., Freedson, P. S., Ward, A., \& Rippe, J. (1990). Ideal to real-Implementing a youth fitness program. Journal of Physical Education. $\underline{\text { Recreation and Dance, }} \underline{61(6), 52-58 .}$

Kraft, R. E. (1989). Fitness tests are only for the fit. Physical Educator, 46 , 18-20.

Kuntzleman, C. \& Reiff, G. (1992). The decline in American children's fitness levels. Research Quarterly for Exercise and Sport, $\underline{63}(2), 107-111$. 
Lawson, H., Lawson, B., \& Stevens, A. (1982). Meanings and functions attributed to elementary physical education. Canadian Association of Health, Physical Education, and Recreation, 48(4), 3-6.

Locke, L. F. (1989). Qualitative research as a form of scientific inquiry in sport and physical education. Research Quarterly for Exercise and Sport, $\underline{60}(1)$, $1-20$.

Loper, D. A., Scheer, J. K., Ansorge, C. J., Bahls, V. M., \& Wandzilak, T. (1989). Healthful living the goal - Physical education the means? Journal of Physical Education, Recreation and Dance, 60(2), 58-61.

Martinek, T. J. \& Griffith, J. B. (1994). Learned helplessness in physical education: A developmental study of causal attributions and task persistence. Journal of Teaching Physical Education, 13, 108-122.

McNally, D. W. (1977). Piaget, Education, and Teaching. Sussex: The Harvester Press.

McSwegin, P.J. (Ed.). (1989). Assessing Physical Fitness. Journal of Physical Education Recreation and Dance, 60(6), 33.

McSwegin, P. J. \& Mielke, D. (1989). Shaping fitness behavior. Journal of Physical Education, Recreation and Dance, 60(6), 64.

McSwegin, P. J., Pemberton, C., \& Petray, C. (1989). An educational plan. Journal of Physical Education, Recreation and Dance, 60(1), 32-34.

Measor, L. (1985). Interviewing: A strategy in qualitative research. In R. Burgess 
(Ed.), Strategies of Educational Research (pp. 55-77). Philadelphia, PA: Falmer.

Meyer, C. A. (1991). What's in a label? Performance assessment or authentic assessment? Educational Leadership $\underline{49}(2), 74$.

Michaud, T. J. \& Andres, F. F. (1990). Should physical education programs be responsible for making our youth fit? Journal of Physical Education, Recreation, and Dance, 61(6), 32-35.

Morine-Dershimer, G. (1985). Talking, listening, and learning in elementary classrooms. New York: Longman.

National Association for Sport and Physical Education. (1992). Developmentally Appropriate Physical Education Practices for Children. A position statement of the Council on Physical Education for Children. Reston, VA: AAHPERD.

Paffenbarger, R. S. \& Hyde, R. T. (1984). Exercise in the prevention of coronary heart disease. Preventive Medicine, 13, 3-22.

Pangrazi, B. (1989). Maintain your resolve--Teach lifetime physical education. Journal of Physical Education,Recreation, and Dance, $60(6), 12$.

Parker, W. C. (1984). Interviewing children: Problems and promise. Journal of Negro Education, 53(1), 18-28.

Pate, R. (1991). Health-related measures of children's physical fitness. Journal of School Health 61(5), 231-233.

Pate, R. R., Ross, J. G., Dotson, C. O., \& Gilbert, G. G. (1985). The new norms. 
Journal of Physical Education, Recreation and Dance, $\underline{56}(1), 28-30$.

Pemberton, C. \& McSwegin, P. J. (1989). Goal setting and motivation. Journal of Physical Education, Recreation and Dance, 60(1), 39-41.

Ratliffe, T. \& Ratliffe, L. (1994). Teaching children fitness: Becoming a master teacher. Champaign: Human Kinetics.

Rogers, D. L. (1987). Encouraging extended conversations with young children. Day Care and Early Education. (Fall): 23-27.

Ross, J. G., \& Gilbert, G. G. (1985). The national children and youth fitness study: A summary of findings. Journal of Physical Education, Recreation, and Dance, $\underline{56}(1), 45-50$.

Ross, J. C. \& Pate, R. R. (1987). The national children and youth fitness study II: A summary of findings. Journal of Physical Education, Recreation and Dance, $\underline{58}(9), 51-56$.

Rowland, T. (1992). Exercise, nutrition, and the prevention of cardiovascular disease: A pediatric perspective. Medicine, Exercise, Nutrition, and Health, $1(1), 34-41$.

Rutherford, W. J. (1990). Issues. Journal of Physical Education, Recreation and Dance, $\underline{61}(9), 15$.

Safrit, M. J. (1990). Introduction to measurement in physical education and exercise science (2nd ed.). St. Louis: Times Mirror/Mosby College. 
Safrit, M. J. \& Looney, M. A. (1992). Should the punishment fit the crime? A measurement dilemma. Research Quarterly for Exercise and Sport, $\underline{63}(2)$, 124-127.

Seda, I. \& Pearson, P. D. (1991). Interviews to assess learner's outcomes. Reading Research and Instruction, $\underline{31}(1), 22-32$.

Siedel, J. V. \& Clark, J. A. (1984). The Ethnograph: A computer program for the analysis of qualitative data. Qualitative Sociology, $7,110-125$.

Simons-Morton, B. G., O’Hara, N. M., Simons-Morton, D. G., \& Parcel, G. S. (1987). Children and fitness: A public health perspective. Research Quarterly for Exercise and Sport, $\underline{58(4), 295-302 .}$

Simons-Morton, B. G., O’Hara, N. M., Parcel, G. S., Huang, I. W., Baranowski, T., \& Wilson, B. (1990). Children's frequency of participation in moderate to vigorous physical activities. Research Quarterly for Exercise and Sport, 61(4), 307-314.

Stephens, T., Jacobs, D. R., Jr., \& White, C. C. (1985). A descriptive epidemiology of leisure time physical activity. Public Health Reports, $\underline{100}, 147-158$.

Symons, C. W. \& Gascoigne, J. L. (1990). The nation's health objectives--A means to school-wide fitness advocacy. Journal of Physical Education, Recreation, and Dance, $61(6), 59-63$.

Tammivaara, J. \& Enright, D. S. (1986). On eliciting information: Dialogues with child informants. Anthropology \& Education Quarterly, 17, 220-238. 
United States Department of Health and Human Services. (1991). Healthy People 2000: National Health Promotion and Disease Prevention Objectives. (USDHHS Publication No. 287-301/21331). Washington, D.C.: U. S. Government Printing Office.

Updyke, W. F. (1992). In search for relevant and credible physical fitness standards for children. Research Quarterly for Exercise and Sport, $\underline{63}$ (2), 112-119.

Walberg, J. \& Ward, D. (1985). Role of physical activity in the etiology and treatment of childhood obesity. Pediatrician, 2, 82-88.

Weiss, M. R., McAuley, E., Ebbeck, V., \& Wiese, D. M. (1990). Self-esteem and causal attributions for children's physical and social competence in sport. Journal of Sport \& Exercise Physiology, 12, 21-36.

Whitehead, J. R. (1989). Fitness assessment results - Some concepts and analogies. Journal of Physical Education, Recreation and Dance, 60(6), 39-43.

Whitehead, J. R. \& Corbin, C. B. (1991). Effects of fitness test type, teacher, and gender on exercise intrinsic motivation and physical self-worth. Journal of School Health, 61(1), 11-16.

Woods, J., Pate, R., \& Burgess, M. (1992). Correlates to performance on field tests of muscular strength. Pediatric Exercise Science, 4 , 302-311.

Yonemura, M. (1974). Learning what children know. Childhood Education, (Nov./Dec.), 64-67. 
Fitness Homework Sheet - School A
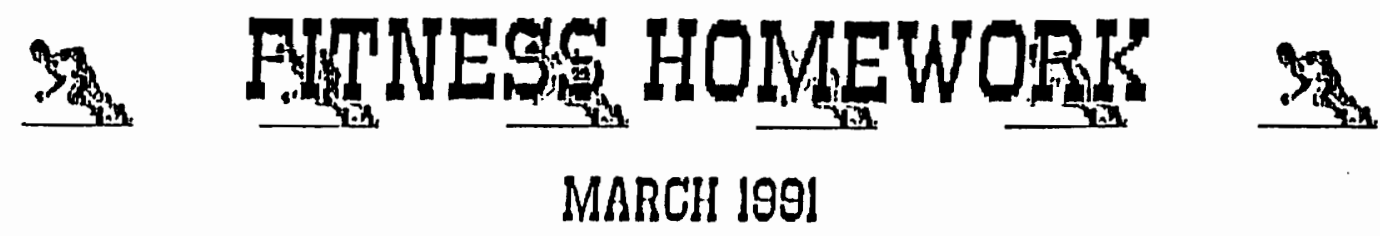

\begin{tabular}{|c|c|}
\hline $\begin{array}{c}\text { JUNDAY } \\
24\end{array}$ & 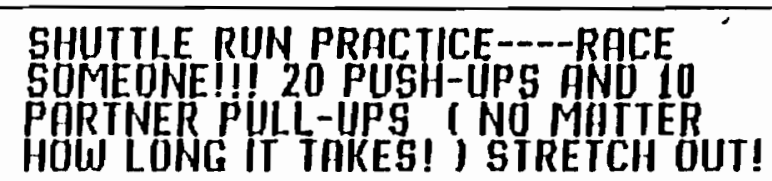 \\
\hline
\end{tabular}

\begin{tabular}{|c|c|}
\hline $\begin{array}{c}\text {. TONDAY } \\
25\end{array}$ & 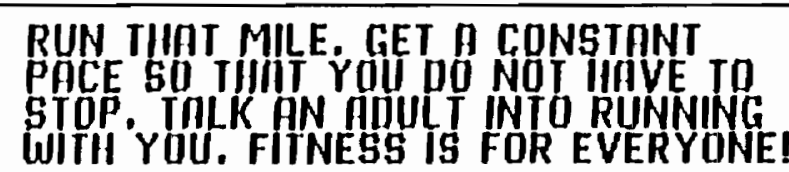 \\
\hline
\end{tabular}

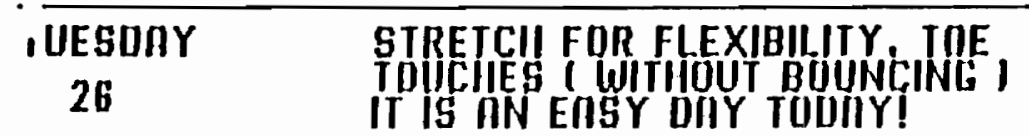

\begin{tabular}{|c|c|}
\hline $\begin{array}{l}\text { WEDNESDAY } \\
27\end{array}$ & $\begin{array}{l}\text { SHUTILE RUN PRACTICE } \\
50 \text { SIT UPG --NU MATTER IIDU LONG } \\
\text { IT TIKKE! } \\
20 \text { PUSI-UPS OR } 10 \text { PARTNER PULL-UP }\end{array}$ \\
\hline $\begin{array}{l}\text { illURSDAY } \\
28\end{array}$ & 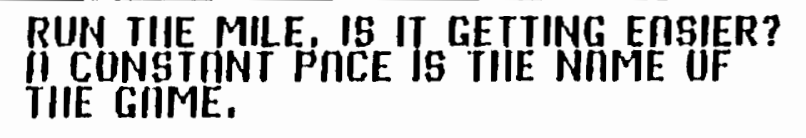 \\
\hline $\begin{array}{c}\text { RIDAY } \\
29\end{array}$ & 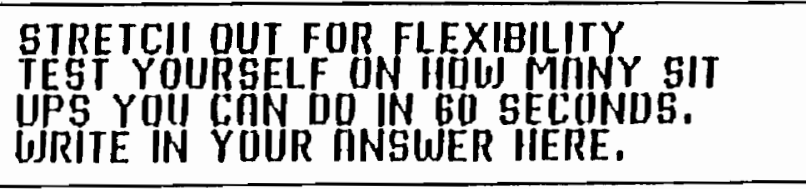 \\
\hline $\begin{array}{l}30 \\
30 \text { ATURDAY }\end{array}$ & 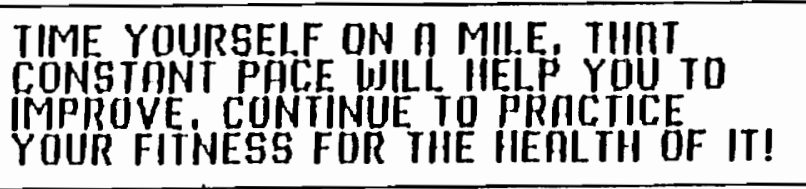 \\
\hline
\end{tabular}

GOOD WJORK!I IMPROVE YOUR FITNESS FOR TIIE IIENLTH OF ITI 


\section{APPENDIX B}

\section{Permission Letter}

April 15, 1991

Dear Parent or Guardian,

I am currently studying for my master's degree in elementary physical education at Virginia Tech in Blacksburg, Virginia. Before this, I taught elementary physical education for four years.

For my graduate research project, I have been talking to children about the physical fitness tests they take in Physical Education. If possible, I would like to talk with your child about this topic one day during the upcoming week (April 22-25). This "interview" will take place during their scheduled physical education class and should last about twenty minutes.

No physical activity will be involved for this interview. If desired, your child will be able to return to their physical education class at any point during the interview. I will be audio-taping the interview; however, the names of your child, their school, and the teachers will remain anonymous during all aspects of the project, and any information gathered will be used only by me for the purposes of this project.

I hope you will give your child permission to participate in this project. To do so, please sign below and have your son/daughter return this form to their p.e. teacher by Thursday, April 18, 1991. I will not be able to talk with them without having this form returned. If you have any questions at all about the project, you can feel free to call me at (703)552-5686 (collect). I really appreciate your time and interest in allowing your child to talk with me. Thank you!

Sincerely,

Christine J. Hopple Virginia Tech
Amanda K.

P.E. Teacher
Lisa Lewin

Principal 
I hereby give permission for my child, , to participate in the physical education project described above at [School A or B] Elementary School.

Parent/Guardian Signature Child's Classroom Teacher 


\section{APPENDIX C}

\section{Questions - Written Quiz}

1. Which physical fitness test that you take measures your cardiorespiratory or cardiovascular fitness?

2. Which physical fitness test that you take measures your abdominal muscle strength and endurance?

3. Which physical fitness test that you take measures your flexibility of your lower back and legs?

4. Which physical fitness test that you take measures your arm and shoulder muscle strength and endurance?

5. Which physical fitness test that you take measures your agility? 


\section{APPENDIX D}

\section{Guiding Questions - Physical Education Teachers}

Administration of the Physical Fitness Tests

*When do you give the PFT?

*How do you prepare the children for the test?

*What do you tell them about the test and test items?

*Do you explain the purposes of the test? How do you

explain this? The purposes of the test items?

${ }^{*}$ How far ahead do you prepare them? Do you ever talk

about this information when testing is not going on?

Do you ever mention the tests or their purposes in

situations which don't involve the tests? Examples?

*Do you send any information home before you give the test?

*How do children react to preparing for the test?

*Explain how you and the teachers administer the test...what would a day

look like?

*How long does it take to administer the test to all the children?

Reporting of Scores

*Do children get their scores when they take the test?

*Do they get written scores? What form do you use?

*When do they get these? 
${ }^{*}$ Can you tell me how you would go about giving these out?

*Do you require that the children use their scores in any way after they are given? How?

Differences in children who tend to score well, vs. poorly, on the tests

${ }^{*}$ How do you think the children who don't seem to score well on the tests react to taking them? Those who tend to score welll?

*How do you feel these two groups feel about the different test items?

*Which items do you feel they like the most? Least? Why? Why not?

\section{Curriculum/others}

*Do you have any written lesson plans, etc. which I can take with me that relate to the PFT?

*How long have you taught elementary physical education? At this school? *How long have you given the PFT? Why do you give this specific test? Do you like to give it? Why or why not?

Would you give the PFT if you didn't have to?

*Do you ever instruct the children in cognitive physical fitness concepts?

When? How do you do this? What is this based on? (Do you have plans??) 


\section{APPENDIX E}

\section{Guiding Questions - Principals}

Purposes of physical education

*What place/purpose do you see physical education as taking in your school?

${ }^{*}$ How would you characterize the physical education program in your school?

*What do you see as the main purpose of physical education?

*Do you see physical fitness as being important?

*What do you see as the differences between the two?

Physical fitness test

*What do you feel the purposes of the physical fitness tests are?

*Do you feel the tests are important for the students to take? Why or why not?

*How do you think the parents react to their children taking the tests? Why?

*How do you think the students react to the tests? Why?

*Do you see the purposes of the physical fitness tests being met? Is there anything you feel would make it more beneficial to the children? Why?

*Are there any administrative changes you make during the week(s) they children take the tests? 


\section{APPENDIX F}

\section{Guiding Questions - Classroom Teachers}

Children's reactions to the Physical Fitness Test

*What do you think the students feel like before the tests? After?

*Do you think they like to take the tests? Why or why not?

*Do you think the tests are beneficial? Do you feel they meet educational objectives?

*Do you feel that your children think physical fitness is important? Why or why not?

*Do your children talk about the tests alot? Do they talk about them only around when they are given?

*How do you think the children in your class who don't score well on them react to the tests? Those who do well? Why do you say this?

*How do the students react to getting their scores? Do you feel those who don't score well react any differently than those who do? Why or why not? ${ }^{*}$ Do you feel the children have a good knowledge about physical fitness and why they take the tests?

Where do you think they get this from?

*Do you feel the physical education program has made a difference in any of the children's exercise habits? Their knowledge about the tests? 


\section{APPENDIX G}

\section{Guiding Questions - Supervisor}

*What do you feel are the philosophies of the programs at the two schools?

*Do you feel either/both schools are "fitness" oriented? Why?

*What do you see as being the importance of the PFT? Do you feel they help reach the educational goal of children? Why?

*If you had to change anything about the tests, from your standpoint, what would you?

*Do either schools do anything different/unique about the physical fitness tests that other schools don't do? What do you think of this?

*How do you see the school board/administration as reacting to the physical fitness tests?

*How do you feel the parents feel about the physical fitness tests? The students? 


\section{VITA}

\section{Christine J. Hopple}

Date of Birth: 02/21/62

My professional experience began while I was an undergraduate student at The Florida State University in Tallahassee, Florida. I majored in physical education, with an emphasis in elementary physical education. Upon a semester of interning at at Faulkner Street Elementary School in New Smyrna Beach, Florida, I gained a teaching position at College Park Primary School in Ocala, Florida teaching elementary physical education to students in grades $\mathrm{K}-2$. While at College Park, I helped continue the school's designation as a (the first) Physical Education Demonstration School for the State of Florida.

After four years of teaching, I enrolled in the graduate program at Virginia Polytechnic Institute and State University in Blacksburg, Virginia, of which this thesis was a part of. After completing my coursework, I then joined Human Kinetics Publishers in Champaign, Illinois as an elementary physical education specialist. My duties include acting as editor of the elementary newsletter Teaching Elementary Physical Education, or TEPE. My continued work and involvement remains focused on how physical education can help each child to develop his or her skills, knowledges, and attitudes in a positive and successful manner.

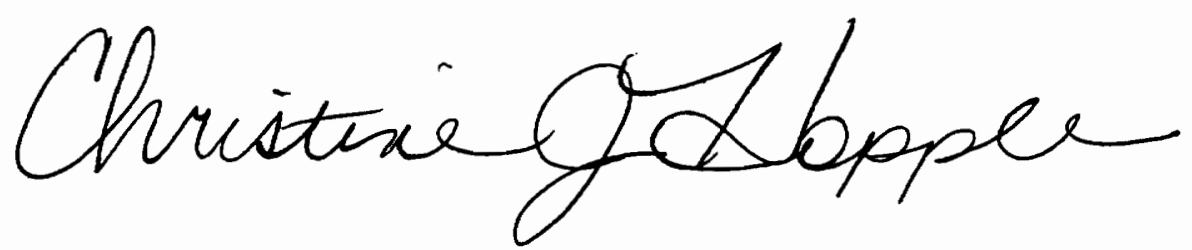

